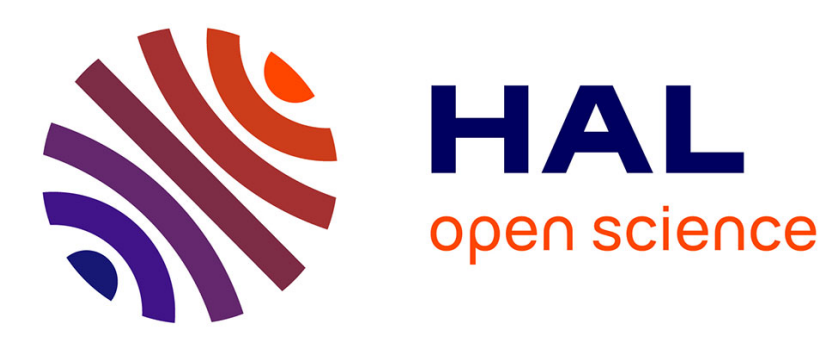

\title{
Carbon nanomaterials applied for the treatment of inflammatory diseases: preclinical evidence
}

Rym Soltani, Shi Guo, Alberto Bianco, Cécilia Ménard-moyon

\section{To cite this version:}

Rym Soltani, Shi Guo, Alberto Bianco, Cécilia Ménard-moyon. Carbon nanomaterials applied for the treatment of inflammatory diseases: preclinical evidence. Advanced Therapeutics, 2020, 3 (9), pp.2000051. 10.1002/adtp.202000051 . hal-03001720

\section{HAL Id: hal-03001720 \\ https://hal.science/hal-03001720}

Submitted on 16 Nov 2020

HAL is a multi-disciplinary open access archive for the deposit and dissemination of scientific research documents, whether they are published or not. The documents may come from teaching and research institutions in France or abroad, or from public or private research centers.
L'archive ouverte pluridisciplinaire HAL, est destinée au dépôt et à la diffusion de documents scientifiques de niveau recherche, publiés ou non, émanant des établissements d'enseignement et de recherche français ou étrangers, des laboratoires publics ou privés. 


\section{Carbon nanomaterials applied for the treatment of inflammatory diseases: preclinical evidence}

Rym Soltani,\# Shi Guo,\# Alberto Bianco, * Cécilia Ménard-Moyon*

\#These authors contributed equally.

R. Soltani, S. Guo, Dr. A. Bianco, Dr. C. Ménard-Moyon

CNRS, Immunology, Immunopathology and Therapeutic Chemistry, UPR 3572, University of Strasbourg, ISIS, 67000 Strasbourg, France

E-mail: a.bianco@ibmc-cnrs.unistra.fr, c.menard@ibmc-cnrs.unistra.fr

Keywords: carbon nanotubes, fullerene, graphene, biosensor, drug delivery

In the last decade graphene-based nanomaterials and carbon dots have joined the family of carbon materials mainly composed of graphite, diamond, fullerene, and carbon nanotubes. Carbon nanomaterials have been widely exploited in various fields from electronics and materials science to nanomedicine. The studies on their effect on the immune system have revealed that they possess intrinsic anti-inflammatory properties reducing the production of proinflammatory cytokines and modulating immune cell maturation. In addition, their large specific surface area associated with high biocompatibility allows their use as carriers for the delivery of anti-inflammatory agents. They can also contribute to the diagnosis of inflammatory diseases as biosensors for low-limit detection and quantification of inflammation-related biomarkers in body fluids and tissues allowing to monitor the concentration of drugs in urine and guide personalized drug usage. Finally, they have been used as adsorbents for blood plasma purification in the clinical treatment of sepsis through efficient removal of certain cytokines. This review focuses on the intrinsic anti-inflammatory properties of carbon nanomaterials. An overview is provided on their use as carriers of anti-inflammatory drugs, as biosensors, and for blood purification in the context of inflammatory diseases. The potential of carbon nanomaterials for clinical translation is also critically discussed. 


\section{Introduction}

Nanotechnology, a multidisciplinary scientific field combining chemistry, physics and biology, deals with a variety of materials at the nanometer scale, which possess novel properties not observed in their bulk forms. Carbon nanomaterials have attracted great attention since many years (Figure 1). ${ }^{[1-2]}$ Nanodiamonds (NDs) were first synthesized accidentally in 1963 during nuclear explosions using carbon-based trigger explosives. ${ }^{[3]}$ The size, shape, and structure of NDs can vary depending on the production method, mainly detonation and the high pressure/high temperature (HPHT) process. ${ }^{[4]}$ NDs synthesized by detonation are constituted of a $\mathrm{sp}^{3}$ carbon core and a surface shell partially composed of $\mathrm{sp}^{2}$ carbon atoms with some impurities and defects. Their size is usually $\sim 5 \mathrm{~nm}$ and they have a round or oval shape. NDs produced by the HPHT process have a broader size distribution, an irregular shape, and a higher purity. They possess a lower quantity of $\mathrm{sp}^{2}$ carbon atoms compared to the detonation-NDs. Fullerene (named also buckyball) was discovered in 1985 and consists of carbon atoms connected by single and double bonds forming a hollow sphere. ${ }^{[5]}$ The most well-known fullerene is composed of 60 carbon atoms $\left(\mathrm{C}_{60}\right)$ with 20 hexagonal and 12 pentagonal faces. The elongated form of buckyballs, namely carbon nanotubes (CNTs), were identified in 1991 by S. Iijima. ${ }^{[6,7]}$ A CNT consists of a sheet of carbon atoms arranged in hexagonal rings forming a cylindrical structure. According to the number of layers, CNTs are classified as single-walled CNTs (SWCNTs) or multi-walled CNTs (MWCNTs) with a length of several micrometers and a diameter between $\sim 1 \mathrm{~nm}$ and tens of nanometers. Few years after, graphene, which is composed of a single atomic layer of $\mathrm{sp}^{2}$-hybridized carbon atoms in the form of a twodimensional hexagonal lattice, was discovered. ${ }^{[8,9]}$ The oxidized form of graphene, graphene oxide (GO), has been extensively used for biomedical applications due to its high water dispersibility and ease of preparation. Other types of carbon nanomaterials have also been isolated such as carbon nanohorns (CNHs) made of SWCNTs with long cone-shaped tips of 2 $\mathrm{nm}$ diameter and a length of $40-50 \mathrm{~nm},{ }^{[10]}$ as well as carbon dots $(\mathrm{CDs})^{[11]}$ and graphene 
quantum dots (GQDs). ${ }^{[12,13]} \mathrm{CDs}$, identified accidentally in 2004 by Scrivens et al. during the purification of SWCNTs, ${ }^{[14]}$ are quasi-spherical amorphous or nanocrystalline nanoparticles with a diameter generally below $10 \mathrm{~nm}$. GQDs, initially reported by $\mathrm{Wu}$ and coworkers, ${ }^{[15]}$ resemble the crystalline structure of single- or few-layer graphene with an elliptical or circular shape and a lateral size dimension of typically a few nanometers. ${ }^{[16]}$

Owing to their unique physicochemical, electrical, optical, mechanical, and structural properties, carbon nanomaterials are attractive for numerous industrial applications especially in electronics, ${ }^{[17]}$ materials science, ${ }^{[18]}$ solar energy conversion, ${ }^{[19]}$ optical sensing, ${ }^{[20]}$ and nanomedicine. ${ }^{[21,22]}$ In particular, they have been exploited for cancer therapy as drug delivery systems and photothermal agents, ${ }^{[23,24]}$ as well as for biosensing ${ }^{[25]}$ and tissue regeneration (Figure 2). ${ }^{[26]}$ In addition, the intrinsic optical and electronic properties of carbon nanomaterials make them useful for a variety of imaging modalities such as magnetic resonance imaging, near-infrared fluorescence, photoacoustic tomography, as well as photothermal and Raman imaging. ${ }^{[27-31]}$ The impact of carbon nanomaterials on immune cells is critical in terms of clinical translation. ${ }^{[32]}$ Functionalized CNTs have shown intrinsic immunostimulatory properties. ${ }^{[33,34]}$ They are able to stimulate immune cells offering future perspectives for their application as immunotherapeutic agents and/or as adjuvants in vaccine therapy for cancer and infectious diseases. Other studies have demonstrated that CNTs functionalized with an antigenic epitope from the foot-and-mouth disease virus was immunogenic in vivo eliciting antibody responses of the right specificity, showing their potential as a delivery system of vaccine antigens. ${ }^{[35,36]}$ The impact of GO with different lateral sizes and functional groups on immune cells has been investigated. ${ }^{[37]}$ For instance, exposure of immune cells to GO led to the upregulation of critical genes involved in immune responses and to the release of cytokines. ${ }^{[38]}$ These effects could be exploited for immune modulation, for example in cancer immunotherapy ${ }^{[39]}$ and also in the emerging field of osteoimmunology for bone-related disorders. The intrinsic immune properties of GO have recently been combined with the 
osteoinductive capacity of calcium phosphate resulting in the activation of monocytes to improve bone regeneration. ${ }^{[40]}$

Carbon nanomaterials have been extensively exploited in cancer therapy. Nevertheless, only few publications have described their use to tackle inflammatory-related diseases. In this context, this review covers the use of different types of carbon nanomaterials toward the treatment of inflammation-associated pathologies. In the first section, the intrinsic properties of different types of carbon nanomaterials are discussed in terms of their ability to reduce inflammation. The second section highlights the studies being conducted on carbon nanomaterials used as carriers for the delivery of anti-inflammatory agents. The following sections evaluate their use as platforms for biosensing applications and for blood purification. Finally, in the last section we give an overview on the nanomedicines that are clinically approved or currently in clinical trials for the treatment of inflammatory diseases. We also provide a critical opinion on the potential of carbon nanomaterials for clinical translation and the issues to overcome in order to meet this challenge.

\section{Intrinsic anti-inflammatory properties of carbon nanomaterials}

Although the biocompatibility of nanomaterials is still a major concern, especially on their impact on the innate immune system, recent studies have shown that some carbon nanomaterials did not activate the inflammasome, a multiprotein cluster of the innate immune system responsible for the activation of inflammatory responses. ${ }^{[41]}$ Furthermore, some carbon nanomaterials inhibited the inflammation process under optimized conditions. These intrinsic anti-inflammatory properties could be indeed exploited for the treatment of anti-inflammatory diseases. Table 1 summarizes the studies exploiting the anti-inflammatory properties of different types of carbon nanomaterials. 


\subsection{Fullerenes}

Thanks to its $\pi$-conjugated $\mathrm{C}=\mathrm{C}$ bonds between hexa- and pentagonal structures, $\mathrm{C}_{60}$ fullerene has the capacity to trap free radicals. ${ }^{[42]}$ It has been widely investigated for its inherent powerful anti-oxidant properties, for the treatment of cancer and also inflammatory diseases. ${ }^{[43]}$ As there are many studies reporting the intrinsic anti-inflammatory properties of fullerenes, this section emphasizes on the most important articles since 2015.

Interleukin (IL)-33 contributes to the pathogenesis of chronic autoimmune diseases and inflammatory diseases. It is a cytokine expressed by fibroblasts, macrophages, and mast cells (MC). It is a potent inducer of pro-inflammatory cytokines including IL-6 and it is involved in chronic autoimmune and allergic inflammatory diseases. For these reasons, IL-33 was recently studied as a new target for the treatment of chronic autoimmune diseases such as RA, systemic lupus erythematosus, systemic sclerosis, and inflammatory bowel disease. ${ }^{[44]}$ A water-soluble bis-malonic acid fullerene derivative was prepared and studied for its ability to suppress IL-33induced expression of pro-inflammatory cytokines (e.g. IL-6) in bone marrow-derived mast cells. ${ }^{[45]}$ Water-soluble tetrazolinium-1 assay revealed that the fullerene derivative did not affect the cell viability with or without IL-33 stimulation. It reduced the IL-33-induced expression of IL-6 in a dose-dependent manner, while it did not suppress the IL-33-induced expression of IL13. The expression of IL- 6 mRNA and IL-13 mRNA was analyzed by real-time polymerase chain reaction, confirming that the fullerene derivative inhibited only IL-33-induced IL-6 mRNA expression. It was observed that IL-33 induced expression of IL-13 mRNA through activation of mitogen-activated protein kinases such as p38 and c-Jun N-terminal kinase (JNK). But, the fullerene derivative did not affect this activation and the expression of IL-13. The influence of the fullerene derivative on IL-33-induced nuclear factor- $\kappa \mathrm{B}(\mathrm{NF}-\kappa \mathrm{B})$ activation was also studied. NF- $\mathrm{kB}$ is a protein complex that controls cytokine production. It was clearly observed that the fullerene compound inhibited phosphorylation and effectively reduced 
nuclear localization of $\mathrm{NF}-\kappa \mathrm{B}$ by inhibiting I $\kappa \mathrm{B}$ kinase activation. As tumor necrosis factor (TNF)- $\alpha$ and IL-1 can also activate NF- $\kappa$ B, the inhibitory effect of the bis-malonic acid fullerene was tested on the production of TNF- $\alpha$ and IL-1. The fullerene derivative failed in suppressing NF- $\kappa \mathrm{B}$ activation induced by TNF- $\alpha$ and IL-1, whereas it specifically reduced only the IL-33 signaling pathway. According to these results, it was suggested that the bis-malonic acid fullerene could be a suitable anti-inflammatory drug, for instance for the treatment of IL33-induced inflammatory diseases. Future experiments would be necessary to identify the detailed components of IкB kinase complexes in order to clarify the mechanism of the specific inhibition of IL-33-induced NF- $\kappa$ B activation by the bis-malonic acid fullerene derivative.

Graft-versus-host disease (GVHD) is a medical complication following allogeneic hematopoietic cell transplantation from a genetically different person. This disease is associated with substantial morbidity and mortality that limit the transplantation. Indeed, the current therapies involve high doses of steroids, monoclonal antibodies and immunosuppressive agents, resulting in serious adverse effects related to immunosuppression and infection. Since fullerenes and their water-soluble forms $\left(\mathrm{C}_{60}(\mathrm{OH})_{18-20}\right.$ named fullerol $)$ present antiinflammatory and anti-oxidant effects, researchers have investigated their intrinsic properties in mice with GVHD. ${ }^{[46]}$ Fullerol demonstrated some potential for the treatment of neurodegenerative disorders, cancer, and arthritis. ${ }^{[47]}$ It was able to control inflammatory responses by reducing the levels of inflammatory cytokines and oxidative stress. ${ }^{[48]}$ In this study, two methods were used to induce GVHD in mice, corresponding to a low and a high body irradiation (radioactive source: ${ }^{60} \mathrm{Co}$ ). In the first protocol GVHD mice treated with fullerol showed $80 \%$ survival compared to $100 \%$ mortality in non-treated mice after 26 days of disease induction. The clinical symptoms such as fecal occult blood, diarrhea, apathy, and skin lesions decreased in the fullerol-treated GVHD mice, and the mice did not lose weight. To confirm the positive effect of fullerol on GVHD mice, a high dose of irradiation, which induces a more 
severe disease and requires bone marrow transplantation, was tested. Higher clinical signs were observed in the non-treated GVHD mice with a mortality of $100 \%$, while fullerol-treated mice exhibited less clinical scores and a survival of 67\%. At day 20 the non-treated GVHD mice had liver injuries and inflammatory infiltration, associated with vasodilatation and hepatocyte necrosis, whereas the fullerol-treated GVHD mice showed fewer hepatic damages with decreased liver accumulation of leukocytes. The fullerol was investigated for its antiinflammatory properties by enzyme-linked immunosorbent assay (ELISA). After 20 days of transplantation, the fullerol significantly inhibited the pro-inflammatory cytokines such as TNF- $\alpha$ and interferon $\gamma$ (IFN- $\gamma$ ) and the chemokines (CCL2, CCL3, CCL5) (Figure 3). Moreover, the treatment with fullerol also diminished reactive oxygen species (ROS) levels in the liver. It is well known that bacteria translocation can complicate GVHD and lead to sepsis followed by death. This study revealed that treatment with fullerol inhibited bacterial translocation to the peritoneal cavity, blood and liver, and thus reduced intestinal injuries. It was also shown that fullerol did not interfere with a graft-versus-leukemia response in mice while alleviating GVHD. Together, the use of fullerol in the treatment of murine GVHD effectively reduced clinical symptoms of the disease, decreased pro-inflammatory mediators and ROS level in the liver (Figure 3), showed less hepatic injury, reduced leukocyte accumulation and bacterial translocation. It also did not impair the beneficial effects of the graft against a leukemia cell line, thus suggesting that fullerol could be a promising approach to treat GVHD.

The current treatments of acute colitis are based on 5-aminosalicylic acid, corticosteroids and immunosuppressors associated to severe side effects such as hemorrhages and hepatitis. As alternative, the anti-oxidant effects of fullerene on acute ulcerative colitis were investigated in a rat model. ${ }^{[49]}$ For this purpose, a $\mathrm{C}_{60}$ fullerene aqueous solution (FAS) was prepared using a saturated solution of pure $\mathrm{C}_{60}$ in toluene. The aqueous and organic phases were treated by 
ultrasonication until total evaporation of toluene. No changes in red blood cell parameters or colon damage were observed when healthy rats received FAS either intraperitoneally or intrarectally. However, when FAS was intraperitoneally administered to acute colitis rats, mild diarrhea, less hemorrhage and colon damage were observed in some animals. Microscopic observation revealed reduced signs of colon damage and increased colon mucosa thickness compared to non-treated acute colitis rats. ROS indicators such as malonic dialdehyde (MDA) and protein carbonyl groups (PCG) decreased, suggesting a reduced oxidative stress. A lower permeability of the colon wall was also seen and contributed to epithelial barrier restoration. FAS also attenuated the consequences of hemorrhages such as signs of anemia and increased platelet count. When FAS was intrarectally administered, both macroscopic and microscopic colon damage signs were ameliorated (Figure 4). The integrity of the epithelial barrier was restored and hematological parameters were improved. This meant an increased monocyte count and a decreased content of neutrophil granulocytes. Glutathione/glutathione-Stransferase activities values were close to the control ones, which was indicative of the suppression of lipid peroxidation and of an enhanced liver redox status. The use of FAS decreased the content of neutrophil granulocytes and raised the monocyte content, thus reducing inflammation and contributing to the process of colon tissue restoring. The monocyte count was higher in rats treated intrarectally compared to the rats treated intraperitoneally because of the direct contact of $\mathrm{C}_{60}$ with the colon mucosa. Therefore, the use of a $\mathrm{C}_{60}$ fullerene aqueous solution through intrarectal administration could represent an efficient strategy for the treatment of ulcerative colitis.

Allergic and inflammatory skin diseases such as atopic dermatitis (AD) are mediated by oxidative stress. As $\mathrm{C}_{60}$ shows promise in reducing ROS-dependent inflammation, the antiinflammatory properties of an aqueous solution of $\mathrm{C}_{60}$ was assessed in a mouse model of $\mathrm{AD}$ through two different routes of administration, either by subcutaneous (SC) or epicutaneous 
(EC) application. ${ }^{[50]}$ To prepare an aqueous fullerene solution, $\mathrm{C}_{60}$ was dissolved in $\mathrm{N}$-methylpyrrolidone, mixed with an aqueous solution of L-alanine used as a stabilizing agent followed by extensive dialysis against deionized water. Mice were sensitized epicutaneously with ovalbumin to induce skin inflammation. For both administration routes a significant suppression in the production of immunoglobuline $\mathrm{E}(\mathrm{IgE})$ and T helper 2 (Th2) cytokines such as IL-4 and IL-5, was observed, with a concomitant increase of T helper 1 (Th1) cytokine (IL12 in the EC application only and IFN- $\gamma$ ). The expression of forkhead box P3 (FOXP3), a regulatory T-cell marker, rose significantly in ovalbumin-stimulated mouse splenocytes after treatment with $\mathrm{C}_{60}$, in particular after EC application. In addition, the expression of filaggrin (filament aggregating protein), an important epidermal structural protein, was significantly higher with EC application. Therefore, simultaneous increase of filaggrin and FOXP3 expression led to $\mathrm{AD}$ susceptibility reduction. Histological analysis on removed skin stained with hematoxylin and eosin revealed that the non-treated $\mathrm{AD}$ mice presented the main characteristics of skin lesions such as epidermal thickening and necrosis, as well as cell infiltration of dermis and epidermis with eosinophils, neutrophils, and lymphocytes. With EC application, both leukocyte and eosinophil infiltration decreased, and the other skin lesion symptoms were nearly absent. With SC application, only the leukocyte infiltration and epidermal necrosis decreased. Taken together, these results show that both EC and SC administration of $\mathrm{C}_{60}$ had efficient therapeutic effect in the treatment of $\mathrm{AD}$, although $\mathrm{EC}$ application of $\mathrm{C}_{60}$ was more effective, with approximately $42 \%$ amelioration in allergic inflammation. This difference could be explained by a higher availability of $\mathrm{C}_{60}$ in the immune system because of the presence of a high number of immune cells in the skin in situation of allergic inflammation such as AD.

$\mathrm{NF}-\kappa \mathrm{B}$ is one of the most important regulators of pro-inflammatory gene expression. FC $\gamma$ receptors $(\mathrm{FC} \gamma \mathrm{R})$ is a protein found at the surface of mast cells that contributes to the protective 
functions of the immune system. In this context, a series of forty $\mathrm{C}_{70}$ fullerene derivatives was tested for their capacity to inhibit inflammatory mediators that are released in rheumatoid arthritis (RA) and human osteoclast formation. ${ }^{[51]}$ For this purpose, two mouse models of RA were prepared, a $\mathrm{K} / \mathrm{BxN}$ serum transfer arthritis mouse model and a collagen-induced arthritis (CIA) mouse model. Among the forty derivatives tested for their potential pro-inflammatory mediator inhibition, $15 \%$ were efficient at inhibiting cytokine production and reducing degranulation in FC $\gamma$-stimulated bone marrow-derived mast cells and immune complexesstimulated human connective tissue $\mathrm{MC}_{\mathrm{TC}}$, depending on the functional moieties present on $\mathrm{C}_{70}$. Besides, the fullerene derivatives induced $25 \%$ inhibition of the cytokines released from TNF$\alpha$-challenged synovial fibroblasts. Two of them, an amphiphilic liposomal malonylfullerene (ALM) and a water-soluble $\mathrm{C}_{70}$ functionalized with tetra-glycolic acid (TGA), also inhibited osteoclast formation. Both compounds were selected for the rest of the study since they had the highest water solubility. ALM and TGA effectively inhibited the mitochondrial membrane potential in MC in a dose- and time-dependent manner. Moreover, they prevented ROS production by inhibiting immune complex-induced increase of intracellular ROS levels. These compounds also blocked the $\mathrm{FC} \gamma \mathrm{R}$-mediated activation of $\mathrm{NF}-\kappa \mathrm{B}$ in $\mathrm{MC}$ stimulated with immune complexes. ALM and TGA were injected intravenously to study their organ biodistribution. Due to the functionalization with IRDye $800 \mathrm{CW}$, the fullerene derivatives were localized specifically in the inflamed joints $6 \mathrm{~h}$ after the injection, whereas healthy control mice did not show any fluorescence in the joints (Figure 5). Only a very low amount accumulated in the spleen, kidney, heart, lungs, brain, and liver. Toxicity studies were also performed by measuring the serum activity of liver enzymes such as alanine aminotransferase (ALT) and aspartate transaminase (AST). Elevated serum levels of both enzymes are a sign of liver damage. In this study no liver toxicity was found as there was no difference in ALT/AST levels between the fullerene-treated and non-treated mice. These results were consistent with the serum creatinine activity, a kidney toxicity indicator. The control $\mathrm{K} / \mathrm{BxN}$ serum transfer arthritis mice 
showed inflammatory signs such as hyperplasia and inflammatory infiltrates, while the TGAtreated mice presented less joint inflammatory symptoms. On the contrary, ALM and TGA were not effective in attenuating RA in CIA mice since joint inflammation still persisted. To predict in vivo efficiency, cytokine inhibition and osteoclast development were used as key parameters. After 14 days, ALM and TGA inhibited serum TNF- $\alpha$ levels only in the K/BxN serum transfer arthritis model, thus preventing inflammation. Finally, the fullerene derivatives not only decreased MC activation in vitro, but they were also relatively effective in $\mathrm{MC}$ deficient Cre-Master mice, suggesting that they had intrinsic anti-inflammatory properties on other lineages of arthritis, in synovial fibroblasts and osteoclasts.

Although these studies showed that fullerenes displayed intrinsic anti-inflammatory properties in vivo in different rodent models such as GVHD, acute colitis, atopic dermatitis, and RA models, further investigations are required to understand the structure-activity relationship of the fullerene derivatives, which is dependent on the functional groups present on the fullerenes, and the inhibitory mechanism of the inflammatory diseases.

\subsection{Carbon nanotubes}

Mast cells play a key role in the inflammatory process by releasing pro-inflammatory mediators following immunological stimuli such as biochemical stimuli (e.g., cytokines). As $\mathrm{C}_{60}$ was proved to be effective in suppressing MC-driven inflammatory responses through the inhibition of cellular ROS levels, ${ }^{[52]}$ the inhibitory effect of SWCNTs on MC signaling pathways and proinflammatory mediators was investigated. ${ }^{[53]}$ For this purpose, rat basophilic leukemia (RBL) cells were incubated with pristine SWCNTs. Even after 5 days, the SWCNTs did not alter cellular proliferation. They caused remarkable membrane remodeling in the MC and were surrounded by the MC plasma membrane. The exposure of the RBL cells to SWCNTs caused a decrease in the total cellular clathrin levels in a time-dependent manner. Together with 
clathrin clustering at or near the contact point of the plasma membrane and SWCNTs, this behavior suggested that SWCNTs were internalized via a clathrin-mediated pathway. SWCNT exposure resulted in a significant decrease of degranulation responses in $\mathrm{MC}$, which reduced hypersensitivity and inflammation. Since pro-inflammatory mediators are released in a calcium-dependent manner, both antigen-induced calcium responses in RBL cells and pharmacologically-induced calcium response were inhibited upon incubation with the SWCNTs. Overall, the nanotubes could be potential regulators of mast cell responses.

Atherosclerosis is the narrowing of arteries caused by plaque build-up around the artery wall, which disrupts blood flow in the body and can cause heart attacks and stroke. This is an inflammatory process in which macrophages play an important role and thus represent a promising target for the development of anti-atherosclerotic therapies. Macrophage ablation in atherosclerosis was explored by photodynamic therapy using motexafin lutetium. ${ }^{[54]}$ There are only limited studies using photothermal therapy (PTT) to induce ablation of macrophages in atherosclerosis. SWCNTs display NIR fluorescence and have shown to be effective in the destruction of cancer cells using photothermal therapy. ${ }^{[5]}$ In this context, SWCNTs were investigated for imaging and PTT of vascular inflammation in a murine model. ${ }^{[56]}$ An aqueous suspension of SWCNTs was labeled with cyanine5.5 (Cy5.5) and mixed with phospholipid polyethylene glycol (PL-PEG). RAW 264.7 macrophages were incubated with the SWCNT conjugate and used to study the in vitro macrophage uptake and photothermal ablation. Flow cytometry and confocal microscopy revealed that the SWCNT-Cy5.5 conjugate was taken up by $94 \%$ of macrophages in a dose-dependent manner. Laser light exposure of macrophages incubated with the SWCNT conjugate at $808 \mathrm{~nm}$ led to $93 \%$ of cell death. In vivo uptake and ablation of macrophages were studied in left carotid-ligated friend leukemia

virus B (FVB) mice after induction of diabetes and hyperlipidemia (Figure 6). The mice were imaged by fluorescence molecular tomography before and after the injection of the SWCNT 
conjugate into the tail vain. Images at $48 \mathrm{~h}$ showed an increased fluorescence signal intensity in the left ligated carotids and in the liver compared to the control group of non-ligated mice. Similarly, NIR imaging of the intrinsic SWCNT fluorescence revealed high fluorescence in $e x$ vivo left ligated carotids. Immunohistochemical staining of the ligated mice revealed localization of macrophages in the neointima and adventitia layers, while very little was noticed in the adventitia of the control group. Neointima is a thickened layer of arterial intima formed in atherosclerosis by migration and proliferation of smooth muscle cells. Adventitia is a loose and irregular collagenous connective tissue composed of blood vessels, fibroblasts, nerves, and other components, that participates actively in the development of atherosclerosis. The photothermal treatment performed by exposing the left carotid ligated artery to an $808 \mathrm{~nm}$ laser irradiation for $5 \mathrm{~min}$ led to an increase in the local temperature and the induction of apoptosis of macrophages (Figure 6). These results were not observed in the case of ligated carotids not exposed to SWCNTs or those not exposed to laser irradiation. This study demonstrated that functionalized SWCNTs can act as both imaging and photothermal ablation agents of vascular macrophages.

Compared to fullerenes, less is known about the intrinsic anti-inflammatory properties of CNTs. Nevertheless, their photothermal capacity opens opportunities for the thermal ablation of macrophages in inflammatory disorders such as atherosclerosis.

\subsection{Graphene oxide}

Some studies have demonstrated the ability of GO to induce pro-inflammatory responses, ${ }^{[57-63]}$ whereas a few have reported anti-inflammatory activity. For instance, GO with a lateral dimension between $30 \mathrm{~nm}$ and $3 \mu \mathrm{m}$ showed no toxicity and displayed no pro-inflammatory effect at concentrations up to $25 \mu \mathrm{g} \cdot \mathrm{mL}^{-1} \cdot{ }^{[64]} \mathrm{GO}$ was able to significantly inhibit the release of pro-inflammatory cytokines such as IL-1 $\beta$ and IL-6 in murine immortalized bone-marrow- 
derived macrophages (iBMDMs) (Figure 7). To better understand the mechanism of action of GO, RNA-sequence analyses were performed on iBMDMs treated with GO prior to LPS priming. GO caused a clear effect on the immunometabolism of iBMDMs. The alteration in glycolysis-tricarboxylic acid cycle led to the accumulation of itaconate. This metabolite, which was recently discovered to have an anti-inflammatory effect, caused the activation of a transcription factor nuclear factor erythroid 2-related factor 2 (NRF2), which is known to inhibit the expression of pro-inflammatory cytokines IL-1 $\beta$ and IL-6. The anti-inflammatory properties and biocompatibility of GO was found to depend on its size and concentration. Overall, this study brings insights on the interactions of GO with the innate immune system and proposed a mechanism of action on metabolism and gene regulation. Although further research is still required to fully elucidate the effects of GO on the innate immune system, GO showed an immense potential as anti-inflammatory material for clinical applications and could also be used as a tool to elucidate the inflammatory mechanisms.

In another study, the intrinsic anti-inflammatory properties of GO were exploited for the treatment of sepsis. ${ }^{[65]}$ Invariant natural killer T (iNKT) cells are a group of innate-like T lymphocytes that can produce pro-inflammatory or anti-inflammatory cytokines under antigen stimulation. After injection of GO into mice treated with $\alpha$-galactosylceramide, an iNKT cell agonist, the cytokines produced by the iNKT cells were inhibited. GO regulated a phenotype shift on the iNKT cells by converting them from an IFN $\gamma$-producing inflammatory phenotype to a transforming growth factor $\beta$ (TGF $\beta$ )-producing regulatory phenotype, leading to an expansion of regulatory $\mathrm{T}$ cells. The survival rate of mice in severe septic shock significantly increased after the treatment with GO. This study demonstrated that GO significantly protected mice from $\alpha$-galactosylceramide-induced lethality and it reinforced the possibility of using GO for sepsis therapy and as an adjuvant in immunotherapy by modulating iNKT cell responses. 
Both studies pointed out the great potential of pristine GO as anti-inflammatory agent with applications for sepsis therapy and perspectives in immunotherapy by using GO as adjuvant. Nonetheless, more investigations are necessary to fully assess the impact of GO on the innate immune system.

\subsection{Graphene quantum dots and carbon dots}

Graphene quantum dots produced through electrochemical exfoliation of graphite and with an average lateral size of $24 \mathrm{~nm}$ were shown to suppress pro-inflammatory $\mathrm{T}$ cell responses in vitro. ${ }^{[66]}$ Their biocompatibility was satisfactory at concentrations up to $300 \mu \mathrm{g} \cdot \mathrm{mL}^{-1}$ and significantly inhibited the proliferation and cytokine production by peripheral blood mononuclear cells (PBMCs) stimulated with phytohemagglutinin. The maturation of monocyte-derived dendritic cells (DCs) was modulated by the GQDs. DCs are the most potent antigen-presenting cells able to activate or tolerize antigen-specific T cells. The GQDs mediated the downregulation of DC marker CD1a resulting in a lower production of anti-inflammatory IL-12 after DC maturation, lowering the stimulation of $\mathrm{T}$ cell proliferation and affecting the polarization of naive T cells into the Th2 phenotype but not into anti-inflammatory Th1 cells. In addition, the GQDs increased the tolerogenic capacity of DCs, reduced the production of ROS, decreased the nuclear translocation of the transcription factor NF- $\kappa \mathrm{B}$ in DCs and the activity of the mammalian target of rapamycin (mTOR), thus inducing autophagy. This study showed that the immunoregulatory properties of GQDs could be exploited for the treatment of inflammatory $\mathrm{T}$ cell-mediated diseases such as RA, multiple sclerosis, psoriasis, and experimental autoimmune encephalitis, by developing tolerogenic DC vaccines for instance. These GQDs exhibited the anti-inflammatory properties not only in vitro, but also in vivo in experimental autoimmune encephalomyelitis (EAE), an animal model of immune-mediated central nervous system (CNS) damage. ${ }^{[67]}$ The GQDs significantly reduced the daily mean clinical score, attenuate inflammatory CNS damage, and reduce the incidence of disease 
relapses. As the integrity of the blood-brain barrier (BBB) is disrupted in EAE, the GQDs entered the CNS through damaged BBB and were found to be localized in the lymphocytes of the draining lymph nodes, in the glial cells and the axons of EAE rats. However, no accumulation was found in non-immunized animals where the BBB was intact. The immune infiltration, demyelination, axonal damage, and apoptotic death in the CNS of EAE rats treated with the GQDs were diminished. The GQDs also decreased the number of IFN- $\gamma$-expressing Th1 cells and inhibited the production of pro-inflammatory cytokines. The mitogen-activated protein kinases (MAPK)/Akt signaling was modulated leading to the protection of oligodendrocytes and neurons from $\mathrm{T}$ cell-mediated inflammatory damage. Overall, these results demonstrated that the GQDs could be beneficial for neuroinflammation therapy.

Aspirin is a commonly used non-steroidal anti-inflammatory drug to alleviate pains and aches. To overcome its low solubility in physiological medium and the side effect of gastric damage, fluorescent carbon dots were synthesized from aspirin and hydrazine through a microwave process and the diameter of the resulting nanoparticles were $2.2-5 \mathrm{~nm}$ (Figure 8). ${ }^{68]}$ In vitro experiments showed that the aspirin-based carbon dots (FACDs) inhibited the production of inflammatory cytokines TNF- $\alpha$ and IL-1 $\beta$ in LPS-activated macrophages, while aspirin alone had no effect on IL-1 $\beta$. The anti-inflammatory effect occurred through irreversible acetylation of a serine residue of cyclooxygenase (COX) by blocking the oxygenation of the fatty acid, a COX substrate. This led to the decrease of prostaglandin E2 (PGE $)$ level, a potent inflammatory mediator generated by COX, in a rat acute inflammation model. This model was generated by subcutaneous implantation of a polyester sponge soaked with $1 \%$ carrageenan (a polysaccharide causing inflammation) $30 \mathrm{~min}$ after the administration of FACDs. The inflammatory cell layer in the implant site was significantly decreased after the treatment with the FACDs, clearly demonstrating its excellent anti-inflammatory function. Overall, the FACDs showed higher anti-inflammatory effects compared to aspirin, good biocompatibility, while 
allowing cellular imaging and bioimaging. In addition, they improved the solubility of the drug and minimized the gastric damage side effect, making them promising nanomaterials with antiinflammatory properties.

The emergence of GQDs and CDs has prompted researchers to explore their antiinflammatory properties opening the door to further studies in particular to exploit their potential for neuroinflammation therapy.

\section{Carbon nanomaterials as carriers of anti-inflammatory agents}

In addition to their intrinsic anti-inflammatory properties, carbon nanomaterials can also serve as carriers for therapeutic purposes due to their biocompatibility and high surface area leading to good loading efficiency. Using a carrier overcomes the major issues faced by many drugs or substances including low water solubility and limited biodistribution. Therefore, delivery systems allow the enhancement of their pharmacokinetics and bioavailability. The intrinsic anti-inflammatory properties of carbon nanomaterials combined with drug delivery could lead to a better therapeutic effect and potentially to a synergistic effect in the treatment of inflammatory diseases. Table 2 summarizes the studies exploiting the structural properties of different types of carbon nanomaterials as carriers for the delivery of anti-inflammatory agents.

\subsection{In vitro studies}

Fullerenes have been extensively exploited as carriers for the treatment of inflammatory diseases. We have decided in this section to focus on the most relevant studies since 2008.

Joint damage in RA can be slowed or prevented by treatments using pain killers, antiinflammatory drugs, corticosteroids (e.g., glucocorticoids), synthetic and biologic disease 
modifying anti-rheumatic drugs. However, most treatments require frequent and long-term administration, leading to local and/or systemic side effects. In particular, glucocorticoids such as dexamethasone (DEX) not only suppress the production of pro-inflammatory cytokines, but induce the production of anti-inflammatory IL-10 and promote pro-regenerative activities of macrophages. Nevertheless, glucocorticoid receptors (GRs) are present in the cytoplasm of almost all cells in the body leading to adverse effects. As one of the main producers of proinflammatory cytokines, activated macrophages perpetuate both the innate and adaptive immune response. Hence, targeting glucocorticoids to macrophages would enable to alleviate the side effects associated to off-target delivery resulting in broad immunosuppression. To this aim, macrophages can be targeted using nanoparticles as they are able to recognize and internalize them by phagocytosis. For instance, microparticles and nanoparticles such as liposomes and micelles, have been exploited as carriers of glucocorticoids. But, polymeric nanoparticles can induce complement activation and stimulate a pro-inflammatory response. ${ }^{[69,70]}$ Therefore, the development of nanoparticle platforms with inherent antiinflammatory properties is strongly needed and carbon nanomaterials can provide opportunities as demonstrated in the previous section.

In this context, the ROS scavenging properties of $\mathrm{C}_{60}{ }^{[71]}$ were exploited for the development of an anti-inflammatory nanomedicine conjugated to DEX showing reduced cellular apoptosis. ${ }^{[72]}$ DEX can generate ROS and can bind to the apoptosis-related receptor (glucocorticoid receptor) leading to cell apoptosis. To confirm whether the combination of DEX and $\mathrm{C}_{60}$ could reduce the side effects induced by ROS, DEX was conjugated onto methanofullerene carboxylic acid through an esterification reaction. The anti-inflammatory properties of the drug were not affected after conjugation onto $\mathrm{C}_{60}$ and the cytotoxicity of DEX$\mathrm{C}_{60}$ was lower compared to the free drug on mouse thymocytes. ELISA showed that $\mathrm{C}_{60}$ inhibited the binding between DEX and GR because of steric hindrance, thus resulting in the downregulation of several apoptosis-related genes including IL-6 and NF- $\mathrm{KB}$ and inducing a 
lower cytotoxicity (Figure 9). Immunostaining experiments confirmed the absence of GR in the nucleus. This study showed that conjugating DEX to $\mathrm{C}_{60}$ allowed the preservation of the anti-inflammatory properties of the drug with much lower side effects with potential applications for the treatment of inflammatory and autoimmune diseases such as RA, acute infection, and the inflammatory responses to cardiopulmonary bypass.

In addition, conjugating drugs to $\mathrm{C}_{60}$ can improve their anti-inflammatory effects. Pentoxifylline (PTX), commonly used for cerebrovascular and peripheral vascular disease treatment, is also characterized by anti-inflammatory properties, which are related to its capacity to suppress the synthesis of TNF- $\alpha$ by macrophages via inhibition of the activity of the cyclic adenosine monophosphate-phosphodiesterase (cAMP-PDE). Nitric oxide (NO) and TNF- $\alpha$ are two pro-inflammatory cytokines that are key components in acute and chronic inflammatory processes. The suppression of the production of NO and/or TNF- $\alpha$ are therapeutic approaches to treat inflammatory diseases. The overexpression of these cytokines can induce diseases like RA, psoriasis, multiple sclerosis, and asthma. In this context, it was hypothesized that $\mathrm{C}_{60}$ could reduce NO released by macrophages via ROS scavenging or direct NO quenching. For this purpose, PTX was covalently conjugated to $\mathrm{C}_{60}$ and was shown to preserve the viability of murine reticulum sarcoma cells stimulated with LPS. $\mathrm{C}_{60}-\mathrm{PTX}$ also inhibited the release of the pro-inflammatory cytokine TNF- $\alpha$ and the production of NO. ${ }^{[73]}$ Similarly, the covalent conjugation between thalidomide, another anti-inflammatory drug, and $\mathrm{C}_{60}$ also led to a synergistic anti-inflammatory effect via the suppression of NO and TNF- $\alpha$ production by LPSactivated macrophages. ${ }^{[7]}$ Although thalidomide, a sedative drug, was retracted from the market in the 60 's because of high teratogenicity, research on thalidomide was pursued to exploit its immunomodulatory properties as it has effects on cytokine stimulation and cellmediated immunity. ${ }^{[75]}$ The inhibition of NO production was attributed to the ability of $\mathrm{C}_{60^{-}}$ thalidomide to scavenge intracellular ROS and suppress inducible nitric oxide synthase (iNOS) 
expression, an enzyme catalyzing NO production. Moreover, the conjugate inhibited extracellular signal-regulated kinase (ERK) phosphorylation, thus reducing TNF- $\alpha$ secretion. Therefore, $\mathrm{C}_{60}$ functionalized with PTX or thalidomide could result in a series of potent antiinflammatory agents.

Neural prostheses constituted of implantable microelectrodes have been extensively investigated for the restoration, modification or bypass of a diseased and/or damaged part of the nervous system. Nevertheless, there are some limitations associated to possible neuronal loss and scar formation via inflammatory tissue reaction. The delivery of anti-inflammatory drugs or neurotrophic factors to the implant area can overcome these issues. Systems based on conducting polymers that can release drugs upon electrical stimulation, have been developed. However, they are currently limited by a low drug loading capacity and unsatisfactory release profile (non-steady and non-sustainable). CNTs can bring solutions for such implantable microelectrodes as one of their advantages is their ability to encapsulate drugs in their cavity. For instance, DEX was loaded inside oxidized MWCNTs. ${ }^{[76]}$ The open ends of the nanotubes were sealed by a conductive film consisting of polypropyrrole (PPy) through electropolymerization on a glassy carbon electrode (GCE). Upon electrical stimulation, the PPy films containing DEX@CNTs released more drug in comparison to the PPy films devoid of CNTs. The bioactivity of released DEX was preserved when incubated with highly aggressively proliferating immortalized (HAPI) cells (activated by LPS). The drug also significantly inhibited cell activation and NO release. The loading of CNTs in the PPy films enabled to increase the amount of DEX and to release the drug in a more linear and sustainable manner. Furthermore, the CNTs decreased the impedance of the PPy films, which is useful for applications where the electrode has multiple functions including electrophysiological recording and/or stimulation. Overall, this approach validated the possibility of electricallycontrolled drug release using CNTs. 
Intra-articular injections of corticosteroids are prescribed to treat synovial inflammation in advanced arthritis. But, long-term administration at high doses is associated with serious side effects such as osteoporosis, Charcot arthropathy, and skeletal fractures to name a few. To overcome this issue, MWCNTs were used as carriers of triamcinolone (TA), a corticosteroid used in RA therapy, in order to slow the drug release and induce a longer therapeutic activity resulting in better joint protection. For this purpose, TA was adsorbed onto the surface of polyethylene glycol (PEG)-coated MWCNTs. ${ }^{[77]}$ The amount of drug released from the PEGylated CNTs was evaluated at pH 7 and also at pH 5 in the presence or absence of lysozyme. Noteworthy, slightly acidic $\mathrm{pH}$ (6) is found in the synovial fluid of rheumatoid joints. ${ }^{[78]}$ The entire amount of TA was released in the presence of lysozyme over a period of $50 \mathrm{~h}$, whereas $30 \%$ of the drug was liberated at acidic $\mathrm{pH}$ and only $10 \%$ was released at neutral $\mathrm{pH}$. Lysozyme allowed the enhancement of TA delivery in TNF- $\alpha$-stimulated fibroblast-like synoviocytes (FLSs), cells involved in the pathogenesis of RA, without drug release in the extracellular environment. The combination of CNTs and TA reduced the drug dose 10-fold while maintaining similar suppressive effect on the expression of pro-inflammatory cytokines such as TNF- $\alpha$, IL-6, and IL-1 $\beta$, and of matrix metalloproteinases (MMPs), enzymes inducing bone erosion and cartilage destruction. Similarly, the conjugation of DEX onto PEGylated MWCNTs improved the intracellular delivery of the drug in TNF- $\alpha$-stimulated FLS and highly suppressed pro-inflammatory cytokines and MMPs compared to DEX alone. ${ }^{[79]}$ The drug was preferentially released at $\mathrm{pH} 5$ in the presence of lysozyme. The conjugate was able to inhibit ROS production and avoid mitochondrial membrane damage. Overall, these studies demonstrated that the immobilization of anti-inflammatory drugs onto CNTs enhanced the intracellular delivery of the drugs and reduced inflammation in FLS, thus allowing to overcome the side effects caused by repetitive and long-term administrations of conventional drugs at high doses. 
CNTs have also the ability to deliver drugs in macrophages. These cells have a crucial antiinflammatory role as they can release pro-inflammatory cytokines. Budesonide (BUD) is a glucocorticoid used in the treatment of chronic inflammatory diseases including Crohn's disease, ulcerative colitis or asthma. Nevertheless, it is a highly hydrophobic drug and it has low bioavailability because of extensive first-pass hepatic metabolism, and high dosage is necessary leading to side effects. In this context, a BUD-based amphiphile was adsorbed onto MWCNTs. ${ }^{[80]}$ The CNT-BUD conjugate was internalized in murine macrophages and it strongly inhibited the release of pro-inflammatory cytokine IL-6 by macrophages, thus showing high anti-inflammatory properties. Therefore, the use of MWCNTs could allow the administration of lower drug doses with higher local bioavailability and much less adverse effects.

The combination of GO with nanoparticles can offer novel properties, especially for drug delivery. ${ }^{[81]}$ For instance, a hybrid system composed of GO and gold nanoparticles (Au@GO) were incorporated with zwitterionic chitosan (ZC) under visible light exposure. ${ }^{[82]}$ Zwitterionic polymers are able to suppress inflammation, making them appropriate as drug delivery systems in the treatment of inflammatory diseases. Nystatin, an antibiotic agent, was incorporated in Au@GO-ZC. The intrinsic anti-inflammatory properties of $\mathrm{ZC}$ were preserved after combination with $\mathrm{Au} @ \mathrm{GO}$, while its side effects were reduced. Nystatin may stimulate the production of macrophage inflammatory proteins (MIP). However, when incorporated with Au@GO-ZC, the MIP expression significantly decreased. It was hypothesized that ZC could bind to receptors on cell surface and regulate the expression of MIP by affecting cell signaling pathways. This study suggested a potential for using ZC-modified GO as carrier of antibiotics with anti-inflammatory characteristics. 
In vitro studies on the use of carbon nanomaterials as carriers of anti-inflammatory drugs involved a few covalent fullerene conjugates or non-covalent $\mathrm{CNT}$ or GO conjugates. In the latter case, the high specific surface area of CNTs and GO was exploited for adsorption of a large amount of drugs.

\subsection{In vivo studies}

Folic acid is used as a ligand to target cancer cells because it has the ability to bind the folate receptors overexpressed on activated macrophages in the case of RA with high affinity. Consequently, MWCNTs were functionalized non-covalently with FA and methotrexate (MTX), an anti-inflammatory drug. ${ }^{[83]}$ A significant sustained release $(65.8 \%)$ of the drug from the surface of CNT-FA at pH 7.4 was observed. A carrageenan-induced arthritis rat model was used to study the anti-inflammatory effect of CNT-FA-MTX in vivo through intravenous injection. A higher percentage of arthritis inhibition was observed after the administration of the conjugate compared to the treatment using pristine CNTs or the free drug. This result was explained by a sustained release of the drug that increased its biological half-life. The functionalized CNTs accumulated at a lower amount in the liver, kidney, lung, and spleen in comparison with the pristine CNTs and the free drug. In addition, more drug was found in the arthritic joints of the rats after treatment with CNT-FA-MTX. Hence, CNT-FA could be exploited for the targeted sustained delivery of anti-inflammatory drugs.

Colitis is a digestive disease characterized by the inflammation of the colon. Its symptoms include abdominal pain, diarrhea, and blood in the stool. The cannabinoid 2arachidonoylglycerol (2-AG) is a drug showing great effects on colitis. Nevertheless, it has a poor solubility and it is rapidly hydrolyzed, thus limiting its effectiveness. To overcome this problem, 2-AG was adsorbed onto amino-functionalized MWCNTs and the conjugate was studied for its capacity to enhance the stability and the delivery of the drug through protection 
against rapid hydrolysis and sustained release. ${ }^{[84]}$ A significant reduction of the drug toxicity was shown with 2-AG-CNTs compared to free 2-AG. Intrarectal administration of the CNT conjugates in a rat model 2 days before and 8 days after the induction of colitis revealed a decrease in inflammatory mediators such as cytokines (TNF- $\alpha$, IL-1 $\beta$ ), myeloperoxidase activity, and malondialdehyde content, a marker of lipid peroxidation and oxidative damage. The treatment with CNT-2-AG also ameliorated the colon mucosa injuries and led to a longerlasting therapeutic effect, which provided promising protective effects against colitis.

Atherosclerosis is characterized by the accumulation of apoptotic cells in the necrotic core forming atherosclerotic plaques. Therapies involving prophagocytic antibodies stimulate the phagocytic clearance of apoptotic cells. Nevertheless, they are hampered by toxicity (e.g., anaemia) due to off-target clearance of healthy tissues. Recently, a chemical inhibitor of the antiphagocytic CD47-signal regulatory protein- $\alpha(\mathrm{SIRP} \alpha)$ signaling axis was immobilized on the surface of SWCNTs coated with Cy5.5-labeled PEG. ${ }^{[85]}$ CD47 is upregulated in the atherosclerotic plaques and it drives defective efferocytosis (i.e. clearance of dead cells by macrophages). The functionalized CNTs accumulated in the lesional phagocytes within the atherosclerotic plaque, reactivated efferocytosis locally, and reduced the plaque burden in atherosclerosis mouse models without inducing any significant off-target toxicity. Their preferential internalization in macrophages resulted in increased efferocytosis and consequently in reduced expression of pro-inflammatory chemokines and cytokines and eventually in the clearance of atherosclerotic plaques. The expression of inflammatory genes related to chemokine and cytokine pathways in lesional macrophages was found to be decreased. The enhanced efferocytosis induced by the functionalized CNTs resulting in reduced necrosis in plaques could offer a promising therapeutic strategy for limiting the progression of atherosclerosis. 
Prednisolone (PSL) is a glucocorticoid commonly used to treat inflammatory diseases like RA, lupus, or ulcerative colitis; but it displays many side effects. Single-walled nanohorns (SWCNHs) are characterized by unique physical and chemical properties, especially a large surface area that allows them to be used as carriers for drug delivery. ${ }^{[86]}$ In this study, the in vitro release of PSL previously immobilized on oxidized SWCNHs (o-SWCNHs) was studied. ${ }^{[87]}$ Collagen-induced arthritis rats were used as a model to investigate the antiinflammatory effect of the PSL-o-SWCNH conjugate. First, the SWCNHs were oxidized using a slow combustion method (at 500 and $570^{\circ} \mathrm{C}$ ), which opened the holes on the walls of the SWCNHs. ${ }^{[88]}$ Then, PSL was non-covalently conjugated to o-SWCNHs both outside and inside through a nano-extraction method. Drug loading was 3.2 times higher on o-SWCNHs than on pristine SWCNHs. The release was fast in cell culture media and slow in phosphate buffer saline (PBS), reaching about $40 \%$ and 9\%, respectively. A burst release was also observed in the first hours as a result of PSL adsorbed on the surface of o-SWCNHs, followed by a slow release of the drug encapsulated inside. The functionalized nanohorns were locally injected into tarsal joints of CIA rats. Compared to rats receiving PSL alone or the control group (PBS), arthritis progression was retarded for rats treated with PSL-o-SWCNHs. The number of leukocytes and C-reactive protein level (CRP), which are inflammatory indicators, decreased in rats treated with PSL-o-SWCNHs. Histological analysis of ankle joints showed lower arthritis scores (synovitis, bone destruction, and inflammatory cell infiltration) in the PSL-oSWCNH-treated rats compared to both control groups. Immunohistological analysis using antiCD68 antibody, a marker of osteoclasts, revealed a decreased number of osteoclasts in the ankle joints of the PSL-o-SWCNH-treated rats, while accumulation of osteoclasts was observed in the bone area of the ankle joints in the control group. Overall, these results promote the antiinflammatory effect of PSL-o-SWCNHs and confirm that carbon nanohorns could be used as potential drug delivery candidates. 
Bone morphogenetic protein 2 (BMP-2), an important protein component for articular cartilage maintaining, is crucial for cartilage repairing. However, a high dose of BMP-2 may cause severe side effects such as immune responses, ectopic bone formation, and osteolysis. As a consequence, an appropriate administration of BMP-2 would avoid these issues. When the protein was adsorbed on the surface of GO, the release of BMP-2 was prolonged to 40 days, which decreased the immune response caused by BMP-2. ${ }^{[89]}$ Indeed, the sustained continuous BMP-2 release from the GO surface influenced the progression of cytokines via alleviation of the NF- $\kappa \mathrm{B}$ pathway. The osteoarthritic rats with GO/BMP-2 showed lower Osteoarthritis Research Society International scores compared to the control rats treated with BMP-2 alone. In particular, thicker articular cartilage was observed in the rats treated with GO/BMP-2. Overall, GO/BMP-2 complex efficiently helped cartilage cells to avoid apoptosis in osteoarthritic rats, while preventing the activation of inflammatory factors. Alternative carriers were investigated in other studies for the release of tissue regeneration factors (e.g., BMP-2), including poly(lactic-co-glycolic acid) (PLGA) $)^{[90]}$ and silk. ${ }^{[91]}$ In this case, the release of the regeneration factors was fast and it was insufficient in alleviating the inflammation associated with osteoarthritis. GO presents many advantages as it displays good dispersibility in water, high biocompatibility, and good mechanical strength associated with a large surface area that allows reaching high loadings, making it an ideal platform for drug delivery. This novel strategy for the treatment of osteoarthritis could help avoiding complications leading to more advanced stages of the disease that may involve artificial joint replacement.

Macrophages play an important role in the progression of myocardial infarction (MI) and cardiac repair. Two main phenotypes are involved in cardiac repair, the pro-inflammatory M1 macrophages, which can remove necrotic cells and debris, further initiating inflammatory reactions, and anti-inflammatory M2 macrophages that can produce anti-inflammatory cytokines. Some studies reported the use of stem or dendritic cells to treat MI owing to their 
anti-inflammatory and cardioprotective effects, modulating inflammation and the progression of M2 macrophages to induce cardiac repair. Nevertheless, current cell-based therapies for MI are limited because of multiple shortcomings such as invasive autologous cell isolation, timedemanding and costly ex vivo manipulation of cells, low cell-grafting efficiency, electrophysiological issues after implantation as well as a potential modulation of the whole systemic immune system. ${ }^{[92]}$ As a consequence, immunotherapeutic strategies involving the timely polarization of M1 macrophages toward regenerative M2 phenotype in the MI area are highly necessary. Recombinant proteins were extensively used to induce macrophage polarization. ${ }^{[93]}$ But, the issues associated to local protein delivery and preservation of their biological activity in vivo limited their applications. ${ }^{[94]}$ To overcome these difficulties, different types of carriers were exploited for the targeted delivery of nucleic acids (e.g., DNA, siRNA) for macrophage polarization including exosomes, ${ }^{[95]}$ chitosan, ${ }^{[96]}$ alginate ${ }^{[97]}$ or hyaluronic acid nanoparticles. ${ }^{[98]}$ Besides, the use of nanomaterials with intrinsic anti-inflammatory properties presents additional advantages. In this context, GO was explored as carrier of a plasmid DNA. GO was first conjugated with polyethylene imine (PEI) and folic acid-PEG (FA-PEG) showing a high affinity for activated macrophages and reducing intracellular ROS in immune-stimulated macrophages. ${ }^{[99]}$ An interleukin-4 plasmid DNA, which propagates M2 macrophages, was then adsorbed onto the GO conjugate via electrostatic interactions. The complex induced an early phenotype shift of macrophages from inflammatory M1 phase to reparative M2 phase both in vitro and in vivo in mouse MI models, and thus enhanced secretion of cardiac repair-favorable cytokines (Figure 10). The combination of the anti-inflammatory properties of GO and IL-4 plasmid DNA led to an improvement in fibrosis and heart function.

Chronic inflammation can occur during remodeling in mesenchymal stem cell (MSC)based therapy of cartilage defects, thus hindering cartilage regeneration. TNF- $\alpha$ can suppress the synthesis of cartilage matrix by influencing chondrogenic differentiation and chondrocyte 
apoptosis. Therefore, it is crucial to suppress inflammation, especially the expression of TNF$\alpha$, during MSC-based therapy. CDs are widely used as fluorescent carriers for gene delivery. ${ }^{[100,101]}$ In this context, positively charged CDs were explored as carriers of a remodeling status small interfering RNA (siRNA), namely siTNF- $\alpha$, for the treatment of cartilage defects. ${ }^{[102]}$ The transfection efficiency of the CD-siTNF- $\alpha$ complex in MSCs was higher than using the conventional commercial transfecting agent PEI as carrier, resulting in a higher gene silencing efficiency. The higher transfection efficiency of the CD-siRNA could stem from the small size of the CDs $(4-10 \mathrm{~nm})$ and the aggregation effects upon complexation with the siRNA that could prevent enzymolysis. The CD-siTNF- $\alpha$ upregulated the expression of cartilage-specific genes and thus promoted the chondrogenesis of MSCs. The enhanced therapeutic effect of CD-siTNF- $\alpha$ was also confirmed in vivo in a cartilage defect rat model as it accelerated cartilage regeneration and the boundary between the original cartilage tissue and the neo-tissue was no more distinguishable.

Efficient treatments for fibrosis are highly needed as there are no direct antifibrotic therapeutic interventions so far. Indeed, traditional treatments, for instance corticosteroids and immunosuppressants, are ineffective. Different strategies, including the use of cerium oxide nanoparticles, were developed to act on hepatic cells in order to reduce liver fibrosis. ${ }^{[103]}$ But, they were limited by the issue of specific removal of hepatic collagen while not affecting the inflammatory and healing processes. In this context, an anti-inflammatory plasmid expressing the collagenase matrix metalloproteinase 9 (pMMP-9) was loaded on graphene nanostars (GNSs) functionalized with the fifth-generation poly(amidoamine) (PAMAM-G5) dendrimer through electrostatic interactions with carboxyl groups on their surface (Figure 11). ${ }^{[104]}$ The aim was to induce overexpression of MMP-9 and assess if the pMMP-9-dendrimer-GNSs could be preferentially internalized by inflammatory macrophages in liver fibrotic tracts for boosting the mechanisms of fibrosis regression. GNSs are composed of clusters of conical rolls of 
graphene sheets with cone-shaped tips named nanohorns and they have a diameter of $\sim 100$ nm. ${ }^{[105]}$ The complex was selectively internalized by pro-inflammatory macrophages present in hepatic fibrosis tracts both in vitro and in vivo in cirrhotic mice. The pMMP-9-dendrimer-GNSs significantly stimulated the expression of MMP-9, thus downregulating M1 macrophagerelated gene and inducing the polarization of M1 macrophages to the M2 phenotype. The treatment with pMMP-9-dendrimer-GNS conjugate selectively promoted fibrosis regression and tissue regeneration without causing side effects such as hepatic damage that is usually observed after the treatment with standard anti-inflammatory and antifibrotic drugs, showing the potential of GNSs as carriers for gene therapy.

NDs were also used as carriers for the delivery of DEX. One advantage of NDs is the formation of micron-sized aggregates in physiological conditions, which is the ideal size for internalization by macrophages without induction of pro-inflammatory response. ${ }^{[106]}$ Octadecylamine-functionalized detonation nanodiamonds (ND-ODA) and DEX-adsorbed onto ND-ODA (ND-ODA-DEX) were demonstrated to have significant anti-inflammatory and proregenerative effects in human macrophages in vitro. ${ }^{[107]}$ In addition, ND-ODA (with or without DEX) increased the expression of CD163, which is a phenotype marker of macrophages associated to tissue regeneration. ND-ODA and ND-ODA-DEX were injected in the arthritic limbs of CIA mice at two different doses. ${ }^{[108]}$ At low doses ND-ODA and ND-ODA-DEX induced anti-inflammatory effects despite some variability within groups, thus requiring further investigation to confirm the anti-inflammatory activity of both conjugates in vivo. The bone loss experienced in the non-treated arthritic control mice was not observed in that case. Infiltration of macrophages and expression of pro-inflammatory mediators (iNOS, TNF- $\alpha$ ) were reduced in comparison with the control mice, whereas at higher doses the treatment with ND-ODA increased the expression of these pro-inflammatory markers. Therefore, the dosage should be controlled to avoid inducing a pro-inflammatory response. Nonetheless, ND-ODA 
could be used as carrier with anti-inflammatory intrinsic properties together with drugs such as pro-regenerative molecules to treat chronic inflammatory diseases and induce tissue damage repair. The inherent anti-inflammatory intrinsic properties of NDs were also demonstrated in an in vitro study revealing their potential towards anti-inflammatory implant coatings and devices. $^{[109]}$

All these in vivo studies highlighted the diversity and versatility of carbon nanomaterials as different forms (SWCNTs, MWCNTs, SWCNHs, GO, CDs, graphene nanostars, and NDs) were exploited for the treatment of inflammatory diseases through the non-covalent immobilization of a variety of biologically active molecules (anti-inflammatory drugs, plasmid DNA, small interfering RNA, proteins, chemical inhibitors) on their surface. The combination of these bioactive entities with the intrinsic anti-inflammatory properties of some carbon nanomaterials (depending on their structural and chemical features) provides attractive opportunities to potentially enable novel treatments of inflammatory diseases, as demonstrated in particular by NDs. Of note, fullerenes were not investigated as drug delivery systems in vivo probably due to their lower potential as carriers compared to CNTs and graphene family nanomaterials.

\section{Biosensing}

Electroanalytical methods can find applications for the development of point-of-care devices thanks to their simplicity, low cost, portability, and the possibility of miniaturization. In this context, biosensors based on carbon nanomaterials have been extensively explored for pointof-care early diagnosis of diseases. ${ }^{[110]}$ While they have been widely exploited as immunobiosensors for the detection of cancer biomarkers, ${ }^{[11]}$ they have been investigated to a lower extent in the diagnosis of inflammatory and auto-immune disorders. ${ }^{[112]}$ Early detection 
of inflammatory diseases is important for controlling the progression of the disease and it is crucial for the success of the treatment and for organism repair afterwards. The accurate quantification of lysozyme, cytokines, and other inflammation-related proteins secreted by immune cells is valuable for detecting inflammation. Nevertheless, protein monitoring is challenged by the dynamic secretion process and the low concentration in body fluids or tissues. As carbon nanomaterials display a large surface area allowing to reach high loading efficiency, they can act as signal amplifiers and increase the sensitivity of a biosensor. In addition, as the excess use of non-steroidal anti-inflammatory drugs causes acute side effects, their rapid and sensitive determination is highly important. Table $\mathbf{3}$ summarizes the studies using carbon nanomaterials for the development of biosensors to detect anti-inflammatory drugs and inflammation-related biomarkers.

\subsection{Carbon nanotubes}

Mefenamic acid (MFA) is a non-steroidal anti-inflammatory agent with analgesic, antiinflammatory, and antipyretic properties. It is an inhibitor of cyclooxygenase, an enzyme that synthesizes prostaglandins that are important in pain and inflammatory pathways. MFA has been widely used for the treatment of RA and in Japan for producing a pharmacological closure of symptomatic patent ductus arteriosus in premature infants. A simple, sensitive, and selective electrochemical method using a CNT-modified glassy carbon electrode was developed as sensor for the determination of MFA in urine samples and pharmaceutical formulations using square wave voltammetry. ${ }^{[13]}$ SWCNT-coated GCE had a better electrochemical behavior compared to MWCNT/GCE at fixed concentration of nanotubes, indicating that SWCNTs are better surface modifiers than MWCNTs. The modified GCE displayed a good linear relationship between the peak current and MFA concentration reaching a very low detection limit of $13.4 \mathrm{nM}$ (Figure 12). The developed sensor was exploited for the determination of MFA in both pharmaceutical formulations and human urine samples using only a small amount 
of urine. No interference between the excipients of three tested MFA formulations and the SWCNT/GCE was observed, thus indicating that this type of biosensor is promising to detect the drug in pharmaceutical formulations. Therefore, the SWCNT/GCE could be exploited for therapeutic drug monitoring in patients undergoing a conventional MFA therapy and also in premature neonates with symptomatic patent ductus arteriosus, as well as for pharmacokinetic studies of MFA.

A sensitive, selective, and accurate immunosensor based on SWCNTs coated with an antigenic peptide was developed for the detection of specific autoantibodies in serum from RA patients. ${ }^{[114]}$ For this purpose, SWCNTs were deposited on a quartz crystal microbalance sensing crystal followed by coating with carboxy-terminated Tween20 containing PEG chains to reduce non-specific binding and avoid any denaturing effect of the antigen due to the hydrophobic nature of the SWCNTs, thus preserving the antigenicity of the peptide. The COOH groups of the CNTs were used to covalently anchor by amidation a RA-specific citrullinemodified version of a 14-mer cyclic filaggrin peptide used as the antigen. Autoantibodies to citrulline-containing peptides, in particular citrullinated regions of pro-filaggrin, are relevant in RA. ${ }^{[15,116]}$ A comparison of the performance of the SWCNT-based immunosensor with ELISA and microarray assay systems showed that the immunosensor detected 34.4 and $37.5 \%$ more RA patients with anti-citrullinated peptide antibodies compared to ELISA and microarray, respectively, reflecting an enhanced level of sensitivity attributed to the presence of the SWCNTs. In addition, the chance of a negative test was higher compared to ELISA and microarray (18.4 and 19.6\%, respectively). Thus, the peptide-coated SWCNT-based immunosensor reduced the probability of false negatives. This immunosensor could also be used as a drug screening tool in pharmaceutical formulations. 
Another study demonstrated the use of a SWCNT-based field effect transistor (FET) for the detection of C-reactive protein, ${ }^{[117]}$ an inflammatory biomarker associated with cardiovascular diseases that are the main cause of death worldwide. As a consequence, the monitoring of CRP levels in blood serum is crucial for predicting the risk of cardiovascular diseases. The device was fabricated from a network of SWCNTs bridging FET electrodes. The CRP-specific antibodies were non-covalently immobilized on the surface of the SWCNTs, thus preserving the electronic properties of the nanotubes. The SWCNT-based immunosensor was able to detect CRP in serum samples of cardiovascular patients $\left(>5 \mu \mathrm{g} \cdot \mathrm{mL}^{-1}\right)$ and also residual CRP levels $\left(<1 \mu \mathrm{g} \cdot \mathrm{mL}^{-1}\right)$ in samples of healthy persons not showing any sign of inflammation. The detection limit $\left(10^{-4} \mu \mathrm{g} \cdot \mathrm{mL}^{-1}\right)$ was found to be $2-3$ orders of magnitude lower than conventional immunoassays (limit of detection (LOD): $0.03-0.2 \mu \mathrm{g} \cdot \mathrm{mL}^{-1}$ ), while the dynamic linear range was 6-fold higher. The LOD was much lower compared to the clinically relevant range of concentrations in serum. In addition, it was also lower in comparison with other systems used for CRP detection such as a magnetic sensor $\left(2.5 \times 10^{-2} \mu \mathrm{g} \cdot \mathrm{mL}^{-1}\right),{ }^{[18]}$ an optical RNA-based aptasensor $\left(5 \times 10^{-3} \mu \mathrm{g} \cdot \mathrm{mL}^{-1}\right),{ }^{[119]}$ and a chemiluminescence-based microfluidic system $\left(1.25 \times 10^{-2} \mu \mathrm{g} \cdot \mathrm{mL}^{-1}\right) .{ }^{[120]}$ Therefore, this immunosensor SWCNT-based FET was a promising addition to the development of point-of-care testing methodologies for high-risk patients.

An aptasensor composed of MWCNTs, PEI, platinum nanoparticles (PtNPs), and an aptamer was developed for the detection of diclofenac (DIF), ${ }^{[121]}$ a non-steroidal antiinflammatory drug that can reduce inflammation and pain (Figure 13). This drug is used as an analgesic after surgery or injuries in acute and chronic joint inflammation. Nonetheless, some severe adverse effects can occur including heart attack and stroke, in particular after long term use. To prepare the modified gold electrode, PEI was adsorbed on the nanotube surface followed by in situ formation of PtNPs. Metal nanoparticles, in particular PtNPs, can accelerate 
electron transfer. A suspension of PtNP-PEI-CNT hybrid complex mixed with Nafion solution was dropped on the Au electrode surface and the modified electrode was coated with nickel hexacyanoferrate used as a signal probe for detection of DIF, through an electrodeposition method. Finally, a DIF-aptamer was immobilized covalently on the PtNP-PEI-CNT complex via the formation of phosphoramidate bonds between the primary amines of PEI and the phosphate groups of the aptamer. DIF was quantitatively detected by impedance spectroscopy. The binding of the aptamer to DIF induced a conformation change resulting in an inhibition of nickel hexacyanoferrate electron transfer and thus to an increase of the charge transfer resistance. The aptasensor exhibited a detection limit of $2.7 \mathrm{nM}$, which was lower in comparison with other analytical methods such as electrochemistry using CNT-based systems (differential pulse voltammetry, square wave voltammetry), ${ }^{[122-125]}$ capillary electrophoresis involving a carbon fiber microelectrode,${ }^{[126]}$ or potentiometry using an electrode prepared from polypyrrole films ${ }^{[127]}$ for the detection of DIF $(0.02-19 \mu \mathrm{M})$. The superiority of the described aptasensor was explained by the immobilization of PtNP-PEI-CNT complex, which displayed both high conductivity and surface area, on the Au electrode. In addition, the linear range was wider (200$10 \mathrm{nM}$ ) compared to the above-mentioned techniques. The detection of DIF was performed in human urine samples and pharmaceutical preparations. Hence, the developed aptasensor could be used for the detection of DIF in clinical samples.

CNT-based sensors have shown promises for therapeutic drug monitoring and diagnosis purposes through the detection of anti-inflammatory drugs in urine and inflammatory biomarkers (autoantibodies, C-reactive protein) in serum of patients, respectively, giving interesting perspectives for the development of point-of-care testing methodologies for highrisk patients. 


\subsection{Graphene family nanomaterials}

Nimesulide (NIM) is a non-steroidal anti-inflammatory drug with analgesic and antipyretic properties. For instance, it is used for the treatment of RA, osteoarthritis, and inflammation of the genitourinary system. However, excess use of NIM may cause harm to the gastrointestinal, central nervous, and genitourinary system. Therefore, the rapid and sensitive detection of trace level of NIM is highly required. A screen-printed carbon electrode (SPCE) modified with electrochemically reduced graphene oxide nanoribbons (ER-GONRs) was used for the realtime detection of NIM in human urine samples. ${ }^{[128]}$ The electrochemical reduction of NIM was detected by cyclic voltammetry by observing a reversible redox peak. ER-GONR/SPCE exhibited higher sensitivity compared to bare SPCE and MWCNT-modified SPCE with a LOD of $3.5 \mathrm{nM}$, which exceeded the LOD of previously reported MWCNT-based electrodes for NIM sensing. ${ }^{[129,130]}$ The ER-GONR/SPCE allowed quick detection of trace level of NIM in human urine samples with high sensitivity, wide linear range $\left(1.0 \times 10^{-8}\right.$ to $\left.1.50 \times 10^{-3} \mathrm{M}\right)$, and fast response $(<5 \mathrm{~s})$. In comparison to electrodes modified with metallic particles $(5 \%$ bariumdoped $\mathrm{ZnO}_{2}$ or $\left.\mathrm{TiO}_{2}\right),{ }^{[131,132]}$ ER-GONR/SPCE possessed a comparable LOD but with a wider linear range. Overall, the sensor performance of ER-GONR/SPCE was significantly better than the previously reported electrodes for the detection of NIM. In addition, this biosensor overcame the drawbacks of traditional detection approaches using chromatography coupled with spectrometric read-out, which are laborious, long and require pre-concentrating the samples.

The level of lysozyme, present in tissues and body fluids, is increased in many diseases, including inflammatory bowel disease (IBD) and Crohn's disease. Gold electrodes coated with thin films of reduced GO (rGO)-PEI were prepared by electrophoretic deposition allowing to control the thickness and uniformity of rGO deposited on the electrodes. ${ }^{[133]}$ A lysozymespecific aptamer terminated with an azide was covalently grafted on the electrode coated with 
rGO-PEI functionalized with 4-ethynylaniline through click reaction with high efficiency. Lysozyme, one of the biomarkers of IBD, was recognized by the aptamer with a specific sequence, resulting in a conformational change of the aptamer. As a consequence, a change of the electrochemistry readout was detected by the rGO-PEI-aptamer-functionalized electrode through differential pulse voltammetry. The low detection limit of the functionalized electrode was $200 \mathrm{fM}$ for lysozyme sensing in serum samples of patients suffering from IBD, with a wide linear range down to $20 \mathrm{pM}$, showing better performance than other lysozyme sensors modified with nitrogen-doped vertically aligned CNTs or rGO. ${ }^{[134,135]}$ In addition, the method for the construction of the electrode is simple as it can be done without any special equipment and with the possibility for large scale production. The results obtained by the biosensor were analogous to the classic turbidimetric assay, indicating that it is suitable for the analysis of clinical samples. The rGO-PEI-aptamer-coated electrode biosensor presented a good potential for human IBD detection and offered a versatile platform for further investigation of different disease diagnosis by simply changing the aptamer.

Biosensors able to continuously measure levels of specific analytes in vivo are very useful to understand the biological functions in the body. Only sensors for the detection of glucose, lactose, and oxygen were developed so far. ${ }^{[136-138]}$ Cytokines are a broad category of proteins produced by a high number of cells and they are important in cell signaling including immunomodulation. Continuous cytokine sensing is valuable for disease diagnosis, but it is still challenging due to the low cytokine level in physiological conditions. To increase the sensitivity of GO biosensors based on aptamer structural configuration change, an IFN- $\gamma$-specific aptamer probe was prepared. The electro-redox probe $\mathrm{Ru}\left(\mathrm{NH}_{3}\right)_{6}{ }^{3+}$ was trapped inside the base pairs of the aptamer exploiting the selective binding between the amine functions of $\mathrm{Ru}(\mathrm{III})$ and the imine sites in the stem part of the aptamer (Figure 14). ${ }^{[139]}$ The aptamer consisted of stem and loop parts, forming a hairpin-like conformation. In the absence of the target, the loop-stem 
structure was closed and $\mathrm{Ru}(\mathrm{III})$ was trapped in the structure, while in the presence of a complementary hybridization, a conformational change occurred leading to the release of $\mathrm{Ru}(\mathrm{III})$ as signal reporters. The aptamer( $\mathrm{Ru})$ was grafted to a GO-coated glassy carbon electrode. GO served as a signal amplifier since the abundant functional sites on GO surface allows for more aptamer probes to be loaded onto the GCE. When exposed to IFN- $\gamma$, the loop part of the aptamer could specifically bind to IFN- $\gamma$ and open the stem part, thus releasing the redox $\mathrm{Ru}\left(\mathrm{NH}_{3}\right)_{6}{ }^{3+}$ signal molecules. This resulted in an increase of the square wave voltammetry and chronoamperometry signals. Due to the presence of GO, the sensitivity of IFN- $\gamma$ was $16 \mathrm{nA}$ per $\mathrm{pg} \cdot \mathrm{mL}^{-1}$, which was one order of magnitude higher than the electrode without GO (1.6 nA per $\mathrm{pg} \cdot \mathrm{mL}^{-1}$ ). The GO-aptamer-functionalized GCE was recyclable as the signal stopped upon removal of the analyte because the aptamer reverted to its original configuration. The sensor was regenerated at least 7 times without loss of IFN- $\gamma$ sensitivity and it displayed wider linear range $\left(1.3-210 \mathrm{ng} \cdot \mathrm{mL}^{-1}\right)$ as well as lower detection limit $\left(1.3 \mathrm{pg} \cdot \mathrm{mL}^{-1}\right.$ secreted by immune cells in cell culture medium) compared to other methods. ${ }^{[140,141]}$ Due to the good biocompatibility of GO, the prepared device was used for in vivo detection of IFN- $\gamma$. For this purpose, the biosensor was implanted subcutaneously into tissue of enteritis mice suffering from inflammation of the intestine. This work was a major advancement toward ubiquitous in vivo real-time sensing.

Similarly to CNTs, different types of graphene-based nanomaterials (GO, rGO, GO nanoribbons) have been exploited for the detection of anti-inflammatory drug molecules and inflammatory biomarkers (lysozyme, cytokine). The feasibility of in vivo sensing of cytokines secreted in living animals was demonstrated in enteritis mice through the design of a GO-based device for sustained amperometric monitoring of IFN- $\gamma$. Overall, carbon nanomaterials have been extensively used for electroanalytical applications thanks to their large specific surface area, high electrical conductivity associated to good thermal and mechanical stability. 


\section{Blood purification}

Many medical conditions such as bacterial and viral infection and sepsis trigger an overactivation of the inflammatory response resulting in an overexpression of proinflammatory cytokines that can be detected in the blood stream. Since there is no effective treatment for sepsis, reducing the level of cytokines including IL-6, IL-8 and TNF- $\alpha$, which are relevant for the development of sepsis, in the blood can be considered for treatment. Blood plasma purification (hemoperfusion) using adsorbent materials allows separating cytokines from the blood.

Different types of cytokine adsorbents have been developed including carbide-derived carbons,${ }^{[142]}$ polymer-derived carbons, ${ }^{[143]}$ polymer adsorbents (e.g., polystyrene, cellulose) ${ }^{[144]}$ and silica ${ }^{[145]}$ as well as commercially available adsorbents such as Adsorba ${ }^{\circledR} 300 \mathrm{C}$ (cellulosecoated activated carbon Norit RBX), CytoSorb ${ }^{\circledR}$ (polystyrene-divinylbenzene porous beads coated with polyvinylpyrrolidone), and $\mathrm{CXV}^{\circledR}$ (activated carbon adsorbent). ${ }^{[146]}$

Alternatively, magnetic separation-based blood purification for rapid and selective removal of cytokines from whole blood is an attractive treatment modality. ${ }^{[147,148,149]}$ Currently, a magnetic haemofiltration system is clinically evaluated. ${ }^{[150]}$ Safety issues due to incomplete particle separation leading to magnetic particles entering circulation have to be taken into account. The potential accumulation in some organs could induce acute and long-term toxic effects such as fibrosis and cancer. In addition, the non-specific adsorption of blood proteins and the possible activation of coagulation and inflammation reactions should also be evaluated and excluded before clinical translation. Nevetheless, magnetic nanoparticles can be designed to enhance their biocompatibility. ${ }^{[151]}$ 
For the application of blood purification, graphene nanoplatelets (GnPs) are one of the most efficient adsorbents up to date due to their large external surface area with mesopores in the range of 2-12 $\mathrm{nm}$. This pore size is suitable for cytokine adsorption. Recently, GnPs were granulated with poly(tetrafluoroethylene) (PTFE) binder to increase their specific area compared to GnPs. ${ }^{[152]}$ The granulation also improved the flow dynamic quality of GnPs and prevented the release of small carbon particles. The PTFE granulated-GnPs (GnP-PTFE) showed satisfactory cytokine adsorption rate in the flow system built for hemoperfusion. The cytokine removal ability was high, up to $80 \%$ for IL-6 and IL-8. However, the adsorption capacity for TNF- $\alpha$ was lower. The removal efficiency decreased from $80 \%$ down to $10 \%$ due to the saturation of surface pores suitable for TNF- $\alpha$ during the adsorption process. In this study, GnP-PTFE proved to be efficient adsorbents for cytokine removal in hemoperfusion treatment with a higher efficiency compared to other carbon-based materials including porous activated carbons and porous polymers. GnP-PTFE adsorbents were more efficient than expanded graphite and other carbon materials under dynamic conditions in terms of adsorption rate and capacity for the three cytokines. The removal efficiency of GnP-PTFE was comparable with commercial materials, but the adsorption was faster. For clinical purpose, $70 \mathrm{~g}$ of GnP-PTFE were enough to treat $3 \mathrm{~L}$ of human blood plasma under dynamic conditions for whole body plasma hemoperfusion. This work demonstrated that GnP-PTFE are promising for fast removal of pro-inflammatory cytokines from blood plasma under clinically relevant flow conditions.

Very recently, the U.S. Food and Drug Administration (FDA) granted authorization to Terumo Blood and Cell Technologies Company and Marker Therapeutics for a blood purification system to treat acute respiratory failure in severe acute respiratory syndrome coronavirus 2 (SARS-CoV-2) (better known as coronavirus disease 2019, COVID-19) patients admitted for intensive care. The system is equipped with Marker Therapeutics' Depuro D2000 Adsorption Cartridge containing activated carbon from virgin coconut shells and non-ionic 
resins. The application of a blood purification system in the treatment of COVID-19 gives perspectives for the rapid developement of other systems to reduce pro-inflammatory cytokines levels for therapy of inflammatory diseases.

\section{Clinical translation of carbon nanomaterials}

The combination of nanotechnology with medicine provides novel opportunities to treat various diseases. The number of nanomedicines in clinical trials is constantly rising. ${ }^{[153-155]}$ Indeed, more than 50 drug formulations containing nanomaterials have been approved by the FDA for clinical use, while hundreds of clinical trials are ongoing. ${ }^{[156]}$ Although the number of FDAapproved and marketed nanomedicines is significant and growing, it is much lower for the treatment of inflammatory diseases,${ }^{[157]}$ while carbon nanomaterials remain mainly at the level of laboratory research.

Some clinical trials have been conducted using carbon nanomaterials for other applications than the treatment of inflammatory diseases leading to the commercialization of one product. Activated carbon particles have been clinically tested and approved as lymph node tracers by the China Food and Drug Administration. The product is known as commercially available Carbon Nanoparticles Suspension Injection $\left(\mathrm{CNSI}^{\circledR}\right)$. It is prepared from carbon black and composed of carbon nanoparticles with a diameter range from 10 to $50 \mathrm{~nm}$ in the form of aggregates ( $150 \mathrm{~nm}$ according to transmission electron microscopy) and an average hydrodynamic radius of $189 \mathrm{~nm} \cdot{ }^{[158,159]} \mathrm{CNSI}^{\circledR}$ has the capacity to migrate fast in lymphatic vessel and accumulate in lymph nodes, which has been applied for tumor drainage lymph node imaging in diverse cancer models. ${ }^{[160-162]}$ It is currently evaluated in many clinical trials for such application. ${ }^{[163]}$ Another type of carbon nanomaterials, NDs, were also investigated in clinical trials. They possess microbicidal properties and they have been exploited in dentistry to endow dental materials with better antimicrobial and mechanical properties. ${ }^{[164]}$ They were 
incorporated into gutta percha, a thermoplastic material that is commonly used for filling root canals. $^{[165]}$ The ND-based biomaterial did not reveal any adverse effects and it was clinically validated. ${ }^{[166,167]}$ No signs of re-infection and no visible impairment of tissue healing appeared. The ND-embedded biomaterial shows real potential for non-surgical root canal therapy to mediate periapical wound healing and to prevent from the risk of re-infection. A second clinical study was recently initiated using the ND-based biomaterial loaded with amoxicillin, an antibiotic used for the treatment of different types of infections caused by bacteria. ${ }^{[168]}$ Other clinical trials that are now ended, were performed using CNTs and fullerenes. For instance, CNTs were used in devices for prosthetic materials ${ }^{[169]}$ or for imaging by exploiting the nanotubes as X-ray source array. ${ }^{[170]}$ Biosensors based on functionalized gold nanoparticles and CNTs were also clinically studied for the detection of Parkinson's disease biomarkers and for gastric lesions. ${ }^{[171]}$ In another study, $\mathrm{C}_{60}$ dissolved in squalane showed antiwrinkle properties in clinical trials, showing that the anti-oxidant properties of fullerenes could be exploited in cosmetics. $^{[172]}$

Thanks to their unique properties, carbon nanomaterials present several advantages over other nanomaterials. Even if they are all composed of carbon, they have different allotropic forms of carbon and they display distinct properties and biological behaviors. The pros and cons of carbon nanomaterials for biomedical applications have been already extensively detailed in some recent reviews. ${ }^{[4,21,173]}$ In summary, an intense research effort is being directed to the use of CNDs and GQDs for imaging and theranostics. ${ }^{[31,174]}$ The small size and biodegradability could fasten the clinical translation of these emerging carbon nanomaterials. ${ }^{[175]}$ The graphene family nanomaterials are also widely investigated for the development of biosensors. ${ }^{[176,177]}$ Some companies are currently developing graphene-based biosensors, but none has any commercial product available yet. CNTs are promising carriers for drug delivery and contrast agents for NIR-II fluorescence imaging. ${ }^{[21,178-181]}$ But, their clinical translation may be 
hampered by their perceived biopersistence and toxicity, although evidence of biodegradation and alleviation of their toxicological profile by functionalization, ${ }^{[182,183]}$ as well as their potential for photothermal therapy, provide attractive opportunities. ${ }^{[24]}$ CNTs can be degraded by peroxidases, as well as by neutrophils and macrophages, although complete biodegradation in the body was not demonstrated yet. ${ }^{[184-186]}$ Both CNTs and the graphene family nanomaterials have also demonstrated some potential for regenerative medicine and tissue engineering. ${ }^{[187-189]}$ The intrinsic fluorescent properties of NDs with high photostability may be exploited further for biomedical imaging and clinical diagnosis. ${ }^{[190,191]}$ As previously mentioned, NDs are also being clinically evaluated for root canal therapy. Though fullerenes were among the first types of carbon nanomaterials investigated for biomedical applications, they are now much less considered, despite some potential for drug delivery. ${ }^{[192]}$ Finally, a small number of studies have been conducted using CNHs as drug delivery systems. ${ }^{[193]}$

Despite substantial preclinical evidences for the translational potential of carbon nanomaterials, more studies are still necessary to obtain a complete understanding of their possible adverse effects and to assess the benefit/risk ratio. This is especially mandatory for applications involving systemic administration. Exhaustive research is required to gain a comprehensive picture of their pharmacokinetics profile, in particular their biodegradation and fate in vivo, which may depend on different physicochemical parameters, and the impact of the biodegradation products on the immunological responses.

\section{Conclusion and perspectives}

From zero-dimensional CDs, GQDs, NDs and fullerenes, quasi 1-dimensional CNTs to 2dimensional graphene and 3-dimensional graphene nanostars and carbon nanohorns, the research on carbon-based nanomaterials has attracted great interest and gained impressive 
development in the last decades. Possessing excellent characteristics, they have shown vast potential in a variety of applications such as nanomedicine, especially cancer therapy, and micro/nanoelectronics. More and more researchers are focusing on the application of carbon nanomaterials, mainly carbon nanotubes, graphene and fullerenes, for anti-inflammatory treatment in preclinical studies. It was revealed that carbon nanomaterials have intrinsic antiinflammatory properties. For instance, they significantly inhibited the production of proinflammatory cytokines such as IL-1 $\beta$, IL-6, and IL-12 expressed by activated DCs or macrophages and increase tolerogenic capacity of DCs. The presence of carbon nanomaterials also modulated the maturation of $\mathrm{T}$ cells to anti-inflammatory Th2 cells. Although the mechanisms of the intrinsic anti-inflammatory properties are still not clear, some studies showed that they could have a distinct effect on the immunometabolism of activated macrophages and thus regulate genes and inhibit the expression of pro-inflammatory cytokines. The large surface area of carbon nanomaterials allows covalently conjugating or immobilizing drugs by adsorption with a high loading rate, and gives also the possibility of multifunctionalization to impart the nanotubes with multiple properties. ${ }^{[194]}$ In this regard, they have been widely used as carriers for drug and gene delivery resulting in enhanced drug pharmacokinetics. ${ }^{[1,173,195]}$ Prolonged drug release enables to decrease side effects during the treatment. Drug delivery combined with the intrinsic anti-inflammatory properties of the carbon nanomaterials may result in a better therapeutic effect. In addition, CNTs and GO were exploited as biosensing platforms by acting as signal amplifiers for the detection of inflammatory biomarkers, such as lysozyme, cytokines, and other inflammation-related proteins secreted by immune cells. Nanomaterials with a high loading efficiency allow more probes to be grafted on the electrodes. Moreover, they can act as signal amplifiers and increase the sensitivity of the biosensors for accurate quantification of biomarkers in body fluids and tissues. The biosensors are able to monitor the concentration of drugs in urine samples, which could guide the selection of the most suitable drug dosage for each patient to prevent the side 
effects caused by an excess of drugs. These results open interesting opportunities for personalized medicine. Finally, carbon nanomaterials have shown promise for the clinical treatment of sepsis by developing adsorbents for blood plasma purification through efficient removal of cytokines.

All these applications illustrate the great potential of carbon nanomaterials for the treatment of inflammatory diseases at the preclinical stage. Although they are still perceived with some skepticism regarding their potential toxicity and environmental impact, their biomedical applications are very promising. ${ }^{[23,173,195]}$ In a recent correspondence published in Nature Nanotechnology entitled "Carbon nanotubes added to the SIN List as a nanomaterial of very high concern" the Swedish non-profit organization ChemSec announced the addition of CNTs to the "Substitute It Now" (SIN) list. ${ }^{[196]}$ Researchers working in the field for almost 20 years have recommended making modifications of the record by precisely defining the specific type of CNTs showing a clear evidence of toxicity. ${ }^{[197-199]}$ CNTs are a diverse class of nanomaterials with various lengths, diameters, and morphologies. The generalization of research results obtained from a very narrow subset of data to make broad claims actually brings confusion. It should be kept in mind that studies showing a lack of toxicity are generally not often published because they are considered as negative results. Some parameters are essential to control for increasing the biocompatibility and safety of CNTs, and more generally carbon nanomaterials, such as their purity, size and type of functionalization. ${ }^{[200,201]}$ Anyhow, further studies are still necessary to get a complete understanding of the pharmacokinetics and toxicological profile of carbon nanomaterials. Human enzymes (e.g., peroxidases) have the capacity to degrade carbon nanomaterials, while other pathways in vivo have been elucidated. ${ }^{[202,203]}$ This biodegradability is favorable to pursue research in nanomedicine and for potential clinical translation. ${ }^{[173]}$ Safeby-design carbon nanomaterials should be developed for future research in the treatment of inflammatory-related diseases. Meanwhile, further studies that could reveal the mechanisms of interactions between the immune system and nanomaterials are greatly required. 
In our opinion, the greatest potential of carbon nanomaterials lies in the development of biosensors for the detection of specific biomarkers providing novel opportunities for diagnosis of inflammatory diseases. Still, some improvements are needed before reaching the market, in particular the stabilization of the nanomaterials within the biosensors in order to limit the risk of systemic release in the case of in vivo implantation. The carbon nanomaterials have also shown preclinical evidence for the treatment of inflammatory diseases thanks to their intrinsic anti-inflammatory properties and/or their capacity to deliver anti-inflammatory drugs. Their application for biosensing and blood purification may be more promising because it will be much easier and faster for such applications to reach the market, while their use as antiinflammatory agents or drug delivery systems would take much more time for approval to be legally marketed, taking into account the considerations previously mentioned on the pharmacokinetics and toxicological profile. We strongly encourage scientists to perform comparative studies involving different types of carbon nanomaterials to fully assess their biomedical potential, in particular for the treatment of inflammatory diseases, and launch clinical trials to eventually interest the healthcare industry and reach the patients.

\section{Acknowledgements}

We gratefully acknowledge the Centre National de la Recherche Scientifique (CNRS), the International Center for Frontier Research in Chemistry (icFRC), and financial support from the Agence Nationale de la Recherche (ANR) through the LabEx project Chemistry of Complex Systems (ANR-10-LABX-0026_CSC). SG is indebted to the Chinese Scholarship Council for supporting his $\mathrm{PhD}$ internship. Hazel Lin is gratefully acknowledged for critical reading.

Received: ((will be filled in by the editorial staff))

Revised: ((will be filled in by the editorial staff)) Published online: ((will be filled in by the editorial staff))

\section{References}

[1] A. Bianco, Y. Chen, E. Frackowiak, M. Holzinger, N. Koratkar, V. Meunier, S. Mikhailovsky, M. Strano, J. Tascon, M. Terrones, Carbon 2020, 161, 373.

[2] M. F. L. De Volder, S. H. Tawfick, R. H. Baughman, A. J. Hart, Science 2013, 339, 535. 
[3] V. V. Danilenko, Phys. Solid State 2004, 46, 595.

[4] G. Reina, L. Zhao, A. Bianco, N. Komatsu, Angew. Chem. 2019, 131, 18084; Angew. Chem. Int. Ed. 2019, 58, 17918.

[5] H. W. Kroto, J. R. Heath, S. C. O'Brien, R. F. Curl, R. E. Smalley, Nature 1985, 318, 162.

[6] S. Iijima, Nature 1991, 354, 56.

[7] K. Kobashi, S. Ata, T. Yamada, D. N. Futaba, T. Okazaki, K. Hata, ACS Appl. Nano Mater. 2019, 2, 4043.

[8] K. S. Novoselov, A. K. Geim, S. V. Morozov, D. Jiang, Y. Zhang, S. V. Dubonos, I. V. Grigorieva, A. A. Firsov, Science 2004, 306, 666.

[9] G. Bottari, M. A. Herranz, L. Wibmer, M. Volland, L. Rodriguez-Perez, D. M. Guldi, A. Hirsch, N. Martín, F. D'Souza, T. Torres, Chem. Soc. Rev. 2017, 46, 4464.

[10] S. Iijima, M. Yudasaka, R. Yamada, S. Bandow, K. Suenaga, F. Kokai, K. Takahashi, Chem. Phys. Lett. 1999, 309, 165.

[11] F. Yuan, S. Li, Z. Fan, X. Meng, L. Fan, S. Yang, Nano Today 2016, 11, 565.

[12] P. Namdari, B. Negahdari, A. Eatemadi, Biomed. Pharmacother. 2017, 87, 209.

[13] Y. Yan, J. Gong, J. Chen, Z. Zeng, W. Huang, K. Pu, J. Liu, P. Chen, Adv. Mater. 2019, $31,1808283$.

[14] X. Xu, R. Ray, Y. Gu, H. J. Ploehn, L. Gearheart, K. Raker, W. A. Scrivens, J. Am. Chem. Soc. 2004, 126, 12736.

[15] D. Pan, J. Zhang, Z. Li, M. Wu, Adv. Mater. 2010, 22, 734.

[16] X. T. Zheng, A. Ananthanarayanan, K. Q. Luo, P. Chen, Small 2015, 11, 1620.

[17] X. Zhang, L. Hou, P. Samori, Nat. Commun. 2016, 7, 11118.

[18] M. S. Balogun, Y. Luo, W. Qiu, P. Liu, Y. Tong, Carbon 2016, 98, 162.

[19] F. Bonaccorso, L. Colombo, G. Yu, M. Stoller, V. Tozzini, A. C. Ferrari, R. S. Ruoff, V. Pellegrini, Science 2015, 347, 1246501. 
[20] S. Kruss, A. J. Hilmer, J. Zhang, N. F. Reuel, B. Mu, M. S. Strano, Adv. Drug Deliv. Rev. 2013, 65, 1933.

[21] N. Panwar, A. M. Soehartono, K. K. Chan, S. Zeng, G. Xu, J. Qu, P. Coquet, K. T. Yong, X. Chen, Chem. Rev. 2019, 119, 9559.

[22] X. Cui, S. Xu, X. Wang, C. Chen, Carbon 2018, 138, 436.

[23] J. Saleem, L. Wang, C. Chen, Adv. Healthc. Mater. 2018, 7, 1800525.

[24] B. P. Jiang, B. Zhou, Z. Lin, H. Liang, X. C. Shen, Chem. Eur. J. 2019, 25, 3993.

[25] R. Shandilya, A. Bhargava, N. Bunkar, R. Tiwari, I. Y. Goryacheva, P. K. Mishra, Bios. Bioelectron. 2019, 130, 147.

[26] M. D. Dozois, L. C. Bahlmann, Y. Zilberman, X. Tang, Carbon 2017, 120, 338.

[27] B. R. Smith, S. S. Gambhir, Chem. Rev. 2017, 11, 901.

[28] M. Hernández-Rivera, N. G. Zaibaq, L. J. Wilson, Biomaterials 2016, 101, 229.

[29] J. M. Yoo, J. H. Kanga, B. Hee Hong, Chem. Soc. Rev. 2015, 44, 4835.

[30] J. Dong, K. Wang, L. Sun, B. Sun, M. Yang, H. Chen, Y. Wang, J. Sun, L. Dong, Sens. Actuator B-Chem. 2018, 256, 616.

[31] J. J. Du, N. Xu, J. L. Fan, W. Sun, X. J. Peng, Small 2019, 15, 1805087.

[32] M. Orecchioni, D. Bedognetti, F. Sgarrella, F. M. Marincola, A. Bianco, L. G. Delogu, J. Transl. Med. 2014, 12, 138.

[33] M. Pescatori, D. Bedognetti, E. Venturelli, C. Ménard-Moyon, C. Bernardini, E. Muresu, A. Piana, G. Maida, R. Manetti, F. Sgarrella, A. Bianco, L. G. Delogu, Biomaterials 2013, 34, 4395.

[34] C. Crescio, M. Orecchioni, C. Ménard-Moyon, F. Sgarrella, P. Pippia, R. Manetti, A. Bianco, L. G. Delogu, Nanoscale 2014, 6, 9599.

[35] D. Pantarotto, C. D. Partidos, R. Graff, J. Hoebeke, J.-P. Briand, M. Prato, A. Bianco, J. Am. Chem. Soc. 2003, 125, 6160. 
[36] D. Pantarotto, C. D. Partidos, J. Hoebeke, F. Brown, E. Kramer, J.-P. Briand, S. Muller, M. Prato, A. Bianco, Chem. Biol. 2003, 10, 961.

[37] M. Orecchioni, D. Bedognetti, L. Newman, C. Fuoco, F. Spada, W. Hendrickx, F. M. Marincola, F. Sgarrella, A. F. Rodrigues, C. Ménard-Moyon, G. Cesareni, K. Kostarelos, A. Bianco, L. G. Delogu, Nat. Commun. 2017, 8, 1109.

[38] M. Orecchioni, D. A. Jasim, M. Pescatori, R. Manetti, C. Fozza, F. Sgarrella, D. Bedognetti, A. Bianco, K. Kostarelos, L. G. Delogu, Adv. Healthc. Mater. 2016, 5, 276.

[39] A. Battigelli, C. Ménard-Moyon, A. Bianco, J. Mater. Chem. B, 2014, 2, 6144.

[40] V. Bordoni, G. Reina, M. Orecchioni, G. Furesi, S. Thiele, C. Gardin, B. Zavan, G. Cunibert, A. Bianco, M. Rauner, L. G. Delogu, Nanoscale, 2019, 11, 19408.

[41] V. Leso, L. Fontana, I. Iavicoli, Toxicol. Appl. Pharmacol. 2018, 355, 80.

[42] N. Gharbi, M. Pressac, M. Hadchouel, H. Szwarc, S. R. Wilson, F. Moussa, Nano Lett. 2005, 5, 2578 .

[43] C. A. Ferreira, N. Dalong, Z. T. Rosenkrans, C. Weibo, Nano Res. 2018, 11, 4955.

[44] S. Wang, L. Ding, S. S. Liu, C. Wang, R. X. Leng, G. M. Chen, Y. G. Fan, H. F. Pan, D. Q. Ye, J. Investig. Med. 2012, 60, 1151.

[45] M. Funakoshi-Tago, Y. Miyagawa, F. Ueda, T. Mashino, Y. Moriwaki, K. Tago, Int. Immunopharmacol. 2016, 40, 254.

[46] P. T. T. Bernardes, B. M. Rezende, C. B. Resende, T. P. De Paula, A. C. Reis, W. A. Gonçalves, E. G. Vieira, M. V. B. Pinheiro, D. G. Souza, M. G. M. Castor, M. M. Teixeira, V. Pinho, PLoS ONE 2015, 10, e0123004.

[47] K. Yudoh, R. Karasawa, K. Masuko, T. Kato, Int. J. Nanomed. 2009, 4, 217.

[48] A. Djordjevic, G. Bogdanovic, Arch. Oncol. 2008, 16, 42.

[49] I. V. Byelinska, H. M. Kuznietsova, N. V. Dziubenko, O. V. Lynchak, T. V. Rybalchenko, Yu. I. Prylutskyy, O. A. Kyzyma, O. Ivankov, V. K. Rybalchenko, U. Ritter, Mater. Sci. Eng. C 2018, 93, 505. 
[50] N. Shershakova, E. Baraboshkina, S. Andreev, D. Purgina, I. Struchkova, O. Kamyshnikov, A. Nikonova, M. Khaitov, J. Nanobiotechnol. 2016, 14, 8.

[51] A. L. Dellinger, P. Cunin, D. Lee, A. L. Kung, D. B. Brooks, Z. Zhou, P. A. Nigrovic, C. L. Kepley, PLoS ONE 2015, 10, e0126290.

[52] J. J. Ryan, H. R. Bateman, A. Stover, G. Gomez, S. K. Norton, W. Zhao, L. B. Schwartz, R. Lenk, C. L. Kepley, J. Immunol. 2007, 179, 665.

[53] E. Y. Umemoto, M. Speck, L. M. N. Shimoda, K. Kahue, C. Sung, A. J. Stokes, H. Turner, Toxicol. Lett. 2014, 229, 198.

[54] D. J. Kereiakes, A. M. Szyniszewski, D. Wahr, H. C. Herrmann, D. I. Simon, C. Rogers, P. Kramer, W. Shear, A. C. Yeung, K. A. Shunk, T. M. Chou, J. Popma , P. Fitzgerald, T. E. Carroll, D. Forer, D. C. Adelman, Circulation 2003, 108, 1310.

[55] R. Singh, S. V. Torti, Adv. Drug Deliv. Rev. 2013, 65, 2045.

[56] H. Kosuge, S. P. Sherlock, T. Kitagawa, R. Dash, J. T. Robinson, H. Dai, M. V. McConnell, J. Am. Heart Assoc. 2012, 1, e002568.

[57] A. Bianco, Angew. Chem. 2013, 125, 5086; Angew. Chem. Int. Ed. 2013, 52, 4986.

[58] Y. Volkov, J. McIntyre, A. Prina-Mello, 2D Mater. 2017, 4, 022001.

[59] X. Zhang, J. Yin, C. Peng, W. Hu, Z. Zhu, W. Li, C. Fan, Q. Huang, Carbon 2011, 49, 986.

[60] H. Yue, W. Wei, Z. Yue, B. Wang, N. Luo, Y. Gao, D. Ma, G. Ma, Z. Su, Biomaterials 2012, 33, 4013.

[61] K. P. Wen, Y. C. Chen, C. H. Chuang, H. Y. Chang, C. Y. Lee, N. H. Tai, J. Appl. Toxicol. 2015, 35, 1211.

[62] J. Ma, R. Liu, X. Wang, Q. Liu, Y. Chen, R. P. Valle, Y. Y. Zuo, T. Xia, S. Liu, ACS Nano 2015, 9, 10498.

[63] M. Xu, J. Zhu, F. Wang, Y. Xiong, Y. Wu, Q. Wang, J. Weng, Z. Zhang, W. Chen, S. Liu, ACS Nano 2016, 10, 3267. 
[64] C. Hoyle, J. Rivers-Auty, E. Lemarchand, S. Vranic, E. Wang, M. Buggio, N. J. Rothwell, S. M. Allan, K. Kostarelos, D. Brough, ACS Nano 2018, 12, 11949.

[65] S. W. Lee, H. J. Park, L. Van Kaer, S. Hong, S. Hong, Sci. Rep. 2018, 8, 10081.

[66] S. Tomic, K. Janjetovic, D. Mihajlovic, M. Milenkovic, T. Kravic-Stevovic, Z. Markovic, B. Todorović-Marković, Z. Spitalsky, M. Micusik, D. Vučević, M. Čolić, V. Trajković, Biomaterials 2017, 146, 13.

[67] J. Tosic, Z. Stanojevic, S. Vidicevic, A. Isakovic, D. Ciric, T. Martinovic, T. KravicStevovic, V. Bumbasirevic, V. Paunovic, S. Jovanovic, B. Todorovic-Markovic, Z. Markovic, M. Danko, M. Micusik, Z. Spitalsky, V. Trajkovic, Neuropharmacology 2019, 146, 95.

[68] X. Xu, K. Zhang, L. Zhao, C. Li, W. Bu, Y. Shen, Z. Gu, B. Chang, C. Zheng, C. Lin, H. Sun, B. Yang, ACS Appl. Mater. Interfaces 2016, 8, 32706.

[69] Q. Wang, J. Jiang, W. Chen, H. Jiang, Z. Zhang, X. Sun, J. Control. Release 2016, 230, 64.

[70] D. V. Devine, K. Wong, K. Serrano, A. Chonn, P. R. Cullis, Biochim. Biophys. Acta 1994, $1191,43$.

[71] N. Gharbi, M. Pressac, M. Hadchouel, H. Szwarc, S. R. Wilson, F. Moussa, Nano Lett. 2005, 12, 2578.

[72] Y. Zhang, L. Wang, Y. Sun, Y. Zhu, Z. Zhong, J. Shi, C. Fan, Q. Huang, ACS Appl. Mater. Interfaces 2013, 5, 5291.

[73] S. T. Huang, J. S. Liao, H. W. Fang, C. M. Lin, Bioorg. Med. Chem. Lett. 2008, 18, 99.

[74] S. T. Huang, C. S. Ho, C. M. Lin, H. W. Fang, Y. X. Peng, Bioorg. Med. Chem. 2008, 16, 8619.

[75] M. Melchert, A. List, Int. J. Biochem. Cell Biol. 2007, 39, 1489.

[76] X. Luo, C. Matranga, S. Tan, N. Alba, X. T. Cui, Biomaterials 2011, 32, 6316.

[77] Y. K. Lee, J. K. Choi, Y. J. Kang, H. W. Kim, S. W. Kim, C. K. Park, D. Khang, S. H. Kim, J. Mater. Chem. B 2016, 4, 1660. 
[78] J. R. Levick, J. Rheumatol. 1990, 17, 579.

[79] Y. K. Lee, S. W. Kim, J. Y. Park, W. C. Kang, Y. J. Kang, D. Khang. Int. J. Nanomed. 2017, 12, 5761 .

[80] S. Foillard, J. Russier, C. Seifert, H. Dumortier, E. Doris, RSC Adv. 2016, 6, 53282.

[81] C. N. D. Quyen, C. Ménard-Moyon, K. Kostarelos, A. Bianco, Biochem. Biophys. Res. Commun. 2015, 468, 454.

[82] J. H. Byeon, J. H. Park, Sci. Rep. 2016, 6, 34890.

[83] J. Kayat, N. K. Mehra, V. Gajbhiye, N. K. Jain, J. Drug Target. 2016, 24, 318.

[84] P. Hassanzadeh, E. Arbabi, F. Atyabi, R. Dinarvand, Life Sci. 2017, 179, 66.

[85] A. M. Flores, N. Hosseini-Nassab, K.-U. Jarr, J. Ye, X. Zhu, R. Wirka, A. L. Koh, P. Tsantilas, Y. Wang, V. Nanda, Y. Kojima, Y. Zeng, M. Lotfi, R. Sinclair, I. L. Weissman, E. Ingelsson, B. R. Smith, N. J. Leeper, Nat. Nanotechnol. 2020, 15, 154.

[86] T. Murakami, K. Ajima, J. Miyawaki, M. Yudasaka, S. Iijima, K. Shiba, Mol. Pharm. 2004, 1, 399.

[87] M. Nakamura, Y. Tahara, Y. Ikehara, T. Murakami, K. Tsuchida, S. Iijima, Nanotechnology 2011, 22, 465102.

[88] J. Fan, M. Yudasaka, J. Miyawaki, K. Ajima, K. Murata, S. Iijima, J. Phys. Chem. B 2006, $110,1587$.

[89] C. Zhong, J. Feng, X. Lin, Q. Bao, Int. J. Nanomed. 2017, 12, 1215.

[90] H. Nie, B. W. Soh, Y. C. Fu, C. H. Wang, Biotechnol. Bioeng. 2008, 99, 223.

[91] H. J. Kim, U. J. Kim, H. S. Kim, C. Li, M. Wada, G. G. Leisk, D. L. Kaplan, Bone 2008, $42,1226$.

[92] V. F. Segers, R. T. Lee, Nature 2008, 451, 937.

[93] K. Kis-Toth, G. M. Rajani, A. Simpson, K. L. Henry, J. Dumont, R. T. Peters, J. Salas, C. Loh, Blood Adv. 2018, 2, 2904.

[94] R. Vaishya, V. Khurana, S. Patel, A. K. Mitra, Expert Opin. Drug Deliv. 2015, 12, 415. 
[95] L. Alvarez-Erviti, Y. Seow, H. F. Yin, C. Betts, S. Lakhal, M. J. A. Wood, Nat. Biotechnol. 2011, 29, 341 .

[96] C. Yang, S. Gao, J. Kjems, J. Mater. Chem. B 2014, 2, 8608.

[97] S. Jain, T. H. Tran, M. Amiji, Biomaterials 2015, 61, 162.

[98] T. H. Tran, R. Rastogi, J. Shelke, M. M. Amiji, Sci. Rep. 2015, 5, 16632.

[99] J. Han, Y. S. Kim, M. Y. Lim, H. Y. Kim, S. Kong, M. Kang, Y. W. Choo, J. H. Jun, S. Ryu, H. Y. Jeong, J. Park, G. J. Jeong, J. C. Lee, G. H. Eom, Y. Ahn, B. S. Kim, ACS Nano 2018, 12, 1959.

[100] S. Taghavi, K. Abnous, S. M. Taghdisi, M. Ramezani, M. Alibolandi, J. Control. Release 2020, 318,158 .

[101] R. Mohammadinejad, A. Dadashzadeh, S. Moghassemi, M. Ashrafizadeh, A. Dehshahri, A. Pardakhty, H. Sassan, S. M. Sohrevardi, A. Mandegary, J. Adv. Res. 2019, 18, 81.

[102] J. Liu, T. Jiang, C. Li, Y. Wu, M. He, J. Zhao, L. Zheng, X. Zhang, Stem Cells Transl. Med. 2019, 8, 724 .

[103] D. Oró, T. Yudina, G. Fernández-Varo, E. Casals, V. Reichenbach, G. Casals, B. González de la Presa, S. Sandalinas, S. Carvajal, V. Puntes, W. Jiménez, J. Hepatol. 2016, 64, 691.

[104] P. Melgar-Lesmes, A. Luquero, M. Parra-Robert, A. Mora, J. Ribera, E. R. Edelman, W. Jiménez, Nano Lett. 2018, 18, 5839.

[105] N. Karousis, I. Suarez-Martinez, C. P. Ewels, N. Tagmatarchis, Chem. Rev. 2016, 116, 4850.

[106] H. Yue, W. Wei, Z. Yue, P. Lv, L. Wang, G. Ma, Z. Su, Eur. J. Pharm. Sci. 2010, 41, 650.

[107] A. E. Pentecost, C. E. Witherel, Y. Gogotsi, K. L. Spiller, Biomater. Sci. 2017, 5, 2131. [108] A. Pentecost, M. J. Kim, S. Jeon, Y. J. Ko, I. C. Kwon, Y. Gogotsi, K. Kim, K. L. Spiller, Regen. Biomater. 2019, 6, 163. 
[109] H. Huang, E. Pierstorff, E. Osawa, D. Ho, ACS Nano 2008, 2, 203.

[110] A. Sanati, M. Jalali, K. Raeissi, F. Karimzadeh, M. Kharaziha, S. S. Mahshid, S. Mahshid, Mikrochim. Acta 2019, 186, 773.

[111] Y. Lai, L. Wang, Y. Liu, G. Yang, C. Tang, Y. Deng, S. Li, J. Biomed. Nanotechnol. 2018, 14, 44.

[112] M. Orecchioni, C. Ménard-Moyon, L. G. Delogu, A. Bianco, Adv. Drug Deliv. Rev. 2016, $105,163$.

[113] P. Tarlekar, S. Chatterjee, J. Electroanal. Chem. 2017, 803, 51.

[114] K. A. Drouvalakis, S. Bangsaruntip, W. Hueber, L. G. Kozar, P. J. Utz, H. Dai, Biosens. Bioelectron. 2008, 23, 1413.

[115] E. Girbal-Neuhauser, J. J. Durieux, M. Arnaud, P. Dalbon, M. Sebbag, C. Vincent, M. Simon, T. Senshu, C. Masson-Bessière, C. Jolivet-Reynaud, M. Jolivet, G. Serre, J. Immunol. 1999, 162,585 .

[116] G. A. Schellekens, B. A. W. de Jong, F. H. J. van den Hoogen, L. B. A. van de Putte, W. J. van Venrooij, J. Clin. Invest. 1998, 101, 273.

[117] C. I. L. Justino, A. C. Freitas, J. P. Amaral, T. A. P. Rocha-Santos, S. Cardoso, A. C. Duarte, Talanta 2013, 108, 165.

[118] M. H. F. Meyer, M. Hartmann, H. J. Krause, G. Blankenstein, B. Mueller-Chorus, J. Oster, P. Miethe, M. Keusgen, Biosens. Bioelectron. 2007, 22, 973.

[119] A. Bini, S. Centi, S. Tombelli, M. Minunni, M. Mascini, Anal. Bioanal. Chem. 2008, 390, 1077.

[120] Y. N. Yang, H. I. Lin, J. H. Wang, S. C. Shiesh, G. B. Lee, Biosens. Bioelectron. 2009, 24, 3091.

[121] H. Derikvand, M. Roushani, A. R. Abbasi, Z. Derikvand, A. Azadbakht, Anal. Biochem. 2016, 513, 77 .

[122] X. Yang, F. Wang, S. Hu, Mater. Sci. Eng. C 2008, 28, 188. 
[123] M. Arvand, T. Gholizadeh, M. Zanjanchi, Mater. Sci. Eng. C 2012, 32, 1682.

[124] M. Goodarzian, M. A. Khalilzade, F. Karimi, V. K. Gupta, M. Keyvanfard, H. Bagheri, M. Fouladgar, J. Mol. Liq. 2014, 197, 114.

[125] A. Afkhami, A. Bahiraei, T. Madrakian, Mater. Sci. Eng. C 2016, 59, 168.

[126] R. Roskar, V. Kmetec, J Chromatogr. B Analyt. Technol. Biomed. Life Sci. 2003, 788, 57.

[127] M. C. Oliveira, E. H. Bindewald, L. H. Marcolino, M. F. Bergamini, J. Electroanal. Chem. 2014, 732, 11 .

[128] M. Govindasamy, V. Mani, S. M. Chen, T. Maiyalagan, S. Selvaraj, S. Y. Lee, W. H. Chang, RSC Adv. 2017, 7, 33043.

[129] C. Wang, X. Shao, Q. Liu, Q. Qu, G. Yang, X. Hu, J. Pharm. Biomed. Anal. 2006, 42, 237.

[130] J. Zhang, X. Tan, D. Zhao, S. Tan, Z. Huang, Y. Mi, Z. Huang, Electrochim. Acta 2010, $55,2522$.

[131] S. D. Bukkitgar, N. P. Shetti, R. M. Kulkarni, M. R. Doddamani, J. Electroanal. Chem. 2016, $762,37$.

[132] S. D. Bukkitgar, N. P. Shetti, R. M. Kulkarni, S. B. Halbhavi, M. Wasim, M. Mylar, P. S. Durgi, S. S. Chirmure, J. Electroanal. Chem. 2016, 778, 103.

[133] Q. Wang, A. Vasilescu, Q. Wang, Y. Coffinier, M. Li, R. Boukherroub, S. Szunerits, ACS Appl. Mater. Interfaces 2017, 9, 12823.

[134] Q. Wang, P. Subramanian, A. Schechter, E. Teblum, R. Yemini, G. D. Nessim, A. Vasilescu, M. Li, R. Boukherroub, S. Szunerits, ACS Appl. Mater. Interfaces. 2016, 8, 9600.

[135] Y. Xiao, Y. Wang, M. Wu, X. Ma, X. Yang, J. Electroanal. Chem. 2013, 702, 49.

[136] W. Zhao, S. Schafer, J. Choi, Y. J. Yamanaka, M. L. Lombardi, S. Bose, A. L. Carlson, J. A. Phillips, W. Teo, I. A. Droujinine, C. H. Cui, R. K. Jain, J. Lammerding, J. C. Love, C. P. Lin, D. Sarkar, R. Karnik, J. M. Karp. Nat. Nanotechnol. 2011, 6, 524. 
[137] B. S. Ferguson, D. A. Hoggarth, D. Maliniak, K. Ploense, R. J. White, N. Woodward, K. Hsieh, A. J. Bonham, M. Eisenstein, T. Kippin, K. W. Plaxco, H. T. Soh, Sci. Transl. Med. 2013, 5, 213ra165.

[138] L. Qiu, T. Zhang, J. Jiang, C. Wu, G. Zhu, M. You, X. Chen, L. Zhang, C. Cui, R. Yu, W. Tan, J. Am. Chem. Soc. 2014, 136, 13090.

[139] C. Cao, R. Jin, H. Wei, W. Yang, E. M. Goldys, M. R. Hutchinson, S. Liu, X. Chen, G. Yang, G. Liu, ACS Appl. Mater. Interfaces 2018, 10, 33078.

[140] Y. Chen, T. S. Pui, P. Kongsuphol, K. C. Tang, S. K. Arya, Biosens. Bioelectron. 2014, $53,257$.

[141] J. Xia, D. Song, Z. Wang, F. Zhang, M. Yang, R. Gui, L. Xia, S. Bi, Y. Xia, Y. Li, L. Xia, Biosens. Bioelectron. 2015, 68, 55.

[142] V. Presser, S. H. Yeon, C. Vakifahmetoglu, C. A. Howell, S. R. Sandeman, P. Colombo, S. Mikhalovsky, Y. Gogotsi, Adv. Healthc. Mater. 2012, 1, 796.

[143] C. A. Howell, S. R. Sandeman, G. J. Phillips, A. W. Lloyd, J. G. Davies, S. V. Mikhalovsky, J. D. Gaylor, Biomaterials 2006, 27, 5286.

[144] M. Song, J. Winchester, R. L. Albright, V. J. Capponi, M. D. Choquette, J. A. Kellum, Blood Purif. 2004, 22, 428.

[145] D. J. Hei, M. A. El Kalay, A. T. T. Lin, B. Kshirsagar, T. B. Okarma, H. W. Blanch, Biotechnol. Bioeng. 1994, 44, 1023.

[146] C. Monard, T. Rimmele, C. Ronco, Blood Purif. 2019, 47, 2.

[147] I. K. Herrmann, A. A. Schlegel, R. Graf, W. J. Stark, B. J. Beck-Schimmer, Nanobiotechnology 2015, 13, 49.

[148] I. K. Herrmann, M. Urner, F. M. Koehler, M. Hasler, B. Roth-Z'Graggen, R. N. Grass, W. J. Stark, Small 2010, 6, 1388.

[149] I. K. Herrmann, R. E. Bernabei, M. Urner, R. N. Grass, B. Beck-Schimmer, W. J. Stark, Nephrol. Dial. Transplant. 2011, 26, 2948. 
[150] ClinicalTrials.gov Identifier: NCT03786536 (Safety and Initial Performance of the MediSieve Magnetic Haemofiltration System).

[151] N. V. S. Vallabani, S. Singh, A. S. Karakoti, Curr. Drug Metab. 2019, 20, 457.

[152] M. Seredych, B. Haines, V. Sokolova, P. Cheung, F. Meng, L. Stone, L. Mikhalovska, S. Mikhalovsky, V. N. Mochalin, Y. Gogotsi, ACS Appl. Bio Mater. 2018, 1, 436.

[153] L. Yan, F. Zhao, J. Wang, Y. Zu, Z. Gu, Y. Zhao, Adv. Mater. 2019, 31, 1805391.

[154] A. C. Anselmo, S. Mitragotri, Bioeng. Transl. Med. 2019, 4, e10143.

[155] S. R. D'Mello, C. N. Cruz, M. L. Chen, M. Kapoor, S. L. Lee, K. M. Tyner, Nat. Nanotechnol. 2017, 12, 523.

[156] T. Lammers, M. Ferrari, Nano Today, 2020, 31, 100853.

[157] S. Wang, J. Lv, S. Meng, J. Tang, L. Nie, Adv. Healthc. Mater. 2020, 9, 1901541.

[158] C. Wang, J. Xie, X. Dong, L. Mei, M. Zhao, Z. Leng, H. Hu, L. Li, Z. Gu, Y. Zhao, Small 2020, 16, 1906915.

[159] P. Xie, S.-T. Yang, T. He, S. Yang, X.-H. Tang, Int. J. Mol. Sci. 2017, 18, 2562.

[160] Y. Lu, J. Y. Wei, D. S. Yao, Z. M. Pan, Y. Yao, PLoS ONE. 2017, 12, e0183834.

[161] X. M. Zhang, J. W. Liang, Z. Wang, J. T. Kou, Z. X. Zhou, Chin. J. Cancer 2016, 35, 33. [162] Y. Wang, H. Deng, H. Chen, H. Liu, Q. Xue, J. Yan, G. Li, J. Am. Coll. Surg. 2015, 221, 923.

[163] ClinicalTrials.gov Identifiers: NCT04312087 (Lateral Neck Lymph Node Mapping in Papillary Thyroid Carcinoma); NCT03778255 (Comparing the Diagnostic Value of Different Lymph Node Tracing Methods in Detecting Sentinel Lymph Node Metastasis in Endometrial Cancer); NCT03778268 (Comparing the Diagnostic Value of Different Lymph Node Tracing Methods in Detecting Sentinel Lymph Node Metastasis in Early Cervical Cancer); NCT03632746 (Verifying the Specificity of the Method Combining Nomogram and Sentinel Lymph Node in Predicting Lymph Node Metastasis in Early Gastric Cancer Patients: a Prospective, Single Arm, Observational Study); NCT03550001 (Prospective Randomized 
Clinical Trial of Carbon Nanoparticles as Lymph Node Tracer in Rectal Cancer After Neoadjuvant Radiochemotherapy); NCT03350945 (Application of Carbon Nanoparticles in Laparoscopic Colorectal Surgery).

[164] P. Makvandi, E. N. Zare, K. Ashtari, A. Moeini, F. R. Tay, L. N. Niu, Acta Biomater. 2020, 101, 69 .

[165] D. K. Lee, S. V. Kim, A. N. Limansubroto, A. Yen, A. Soundia, C. Y. Wang, W. Shi, C. Hong, S. Tetradis, Y. H. Kim, N. Park, M. K. Kang, D. Ho, ACS Nano 2015, 9, 11490.

[166] ClinicalTrials.gov Identifier: NCT02698163 (Nanodiamond Modified Gutta Percha (NDGP) Composite for Non-surgical Root Canal Therapy (RCT) Filler Material Applied by Vertical Condensation Obturation Procedure).

[167] D. K. Lee, T. Kee, Z. Liang, D. Hsiou, D. Miya, B. Wu, E. Osawa, E. K. Chow, E. C. Sung, M. K. Kang, D. Ho, Proc. Natl Acad. Sci. U S A, 2017, 114, E9445.

[168] ClinicalTrials.gov Identifier: NCT03376984 (Nanodiamonds and Antibiotics Modified Gutta-percha (NDGX) for Non-surgical Root Canal Therapy (RCT) Filler Material).

[169] ClinicalTrials.gov Identifier: NCT02328352 (The Buckypaper as a New Device in the Treatment of Some Solid Cancer and Hematopoietic System Tumors and as a New Fixing Device for Prosthetic Surgery. In Vivo Study on Effects of BP Implantation, Preliminary to Human Surgical Applications).

[170] ClinicalTrials.gov Identifiers: NCT02873585 (Clinical Evaluation and Patient Experience of a Stationary Intraoral Tomosynthesis (s-IOT) Unit Using a Carbon Nanotube Xray Source Array); NCT01773850 (Comparison of Carbon Nanotube X-ray Stationary Digital Breast Tomosynthesis and 2-D Digital Mammography in Patients With Known Breast Lesions). [171] ClinicalTrials.gov Identifiers: NCT01246336 (Exploratory Study to Detect Volatile Biomarkers of Idiopathic Parkinson's Disease and Parkinsonism From Exhaled Breath Using a Nanomedical Artificial Olfactory System); NCT01420588 (Study of the Exhaled Breath of Patients With Malignant and Benign Lesions With Na-Nose). 
[172] S. Kato, H. Taira, H. Aoshima, Y. Saitoh, N. Miwa, J. Nanosci. Nanotechnol. 2010, 10, 6769.

[173] K. P. Loh, D. Ho, G. N. C. Chiu, D. T. Leong, G. Pastorin, E. K. Chow, Adv. Mater. 2018, 30, 1802368.

[174] S. Chung, R. A. Revia, M. Zhang, Adv. Mater. 2019, 1904362.

[175] C. Martín, G. Jun, R. Schurhammer, G. Reina, P. Chen, A. Bianco, C. Ménard-Moyon, Small 2019, 15, 1905405.

[176] J. Peña-Bahamonde, H. N. Nguyen, S. K. Fanourakis, D. F. Rodrigues, J. Nanobiotechnology 2018, 16, 75.

[177] E. Morales-Narváez, L. Baptista-Pires, A. Zamora-Gálvez, A. Merkoçi, Adv. Mater. 2017, 29,1604905

[178] C. J. Serpell, K. Kostarelos, B. G. Davis, ACS Cent. Sci. 2016, 2, 190.

[179] Y. Miao, C. Gu, Y. Zhu, B. Yu, Y. Shen, H. Cong, ChemBioChem. 2018, 19, 2522.

[180] G. Hong, S. Diao, A. L. Antaris, H. Dai, Chem. Rev. 2015, 115, 10816.

[181] H. Wan, J. Yue, S. Zhu, T. Uno, X. Zhang, Q. Yang, K. Yu, G. Hong, J. Wang, L. Li, Z. Ma, H. Gao, Y. Zhong, J. Su, A. L. Antaris, Y. Xia, J. Luo, Y. Liang, H. Dai, Nat. Commun. 2018, $9,1$.

[182] M. Chen, X. Qin, G. Zeng, Trends Biotechnol. 2017, 35, 836.

[183] H. Ali-Boucetta, A. Nunes, R. Sainz, M. A. Herrero, B. Tian, M. Prato, A. Bianco, K. Kostarelos, Angew. Chem. 2013, 125, 2330; Angew. Chem. Int. Ed. 2013, 52, 2274.

[184] M. Yang, M. Zhang, Front. Mater. 2019, 6, 225.

[185] D. Elgrabli, W. Dachraoui, C. Ménard-Moyon, X. J. Liu, D. Bégin, S. Bégin-Colin, A. Bianco, F. Gazeau, D. Alloyeau, ACS Nano 2015, 9, 10113.

[186] D. Elgrabli, W. Dachraoui, H. De Marmier, C. Ménard-Moyon, D. Bégin, S. Bégin-Colin, A. Bianco, D. Alloyeau, F. Gazeau, Sci. Rep. 2017, 7, 1. 
[187] M. Tanaka, K. Aoki, H. Haniu, T. Kamanaka, T. Takizawa, A. Sobajima, K. Yoshida, M.

Okamoto, H. Kato, N. Saito, Nanomaterials 2020, 10, 659.

[188] S. Kumar, R. Rani, N. Dilbaghi, K. Tankeshwar, K. H. Kim, Chem. Soc. Rev. 2017, 46, 158.

[189] G. Reina, J. M. González-Domínguez, A. Criado, E. Vázquez, A. Bianco, M. Prato, Chem. Soc. Rev. 2017, 46, 4400 .

[190] J. Zhou, A. I. Chizhik, S. Chu, J. Dayong, Nature 2020, 579, 41.

[191] S. Haziza, N. Mohan, Y. Loe-Mie, A. M. Lepagnol-Bestel, S. Massou, M. P. Adam, X.

L. Le, J. Viard, C. Plancon, R. Daudin, P. Koebel, E. Dorard, C. Rose, F. J. Hsieh, C. C Wu, B. Potier, Y. Herault, C. Sala, A. Corvin, B. Allinquant, H. C. Chang, F. Treussart, M. Simonneau, Nat. Nanotechnol. 2017, 12, 322.

[192] A. Montellano, T. Da Ros, A. Bianco, M. Prato, Nanoscale 2011, 3, 4035.

[193] R. Wang, H. Cui, J. Wang, N. Li, Q. Zhao, Y. Zhou, Z. Lv, W. Zhong, RSC Adv. 2016, $6,47272$.

[194] B. Dinesh, A. Bianco, C. Ménard-Moyon, Nanoscale 2016, 8, 18596.

[195] M. Mohajeri, B. Behnam, A. Sahebkar, J. Cell. Physiol. 2018, 234, 298.

[196] S. F. Hansen, A. Lennquist, Nat. Nanotechnol. 2020, 15, 3.

[197] Nat. Nanotechnol. 2020, 15, 163.

[198] B. Fadeel, K. Kostarelos, Nat. Nanotechnol. 2020, 15, 164.

[199] D. A. Heller, P. V. Jena, M. Pasquali, K. Kostarelos, L. G. Delogu, R. E. Meidl, S. V. Rotkin, D. A. Scheinberg, R. E. Schwartz, M. Terrones, Y. Wang, A. Bianco, A. A. Boghossian, S. Cambré, L. Cognet, S. R. Corrie, P. Demokritou, S. Giordani, T. Hertel, T. Ignatova, M. F. Islam, N. M. Iverson, A. Jagota, D. Janas, J. Kono, S. Kruss, M. P. Landry, Y. Li, R. Martel, S. Maruyama, A. V. Naumov, M. Prato, S. J. Quinn, D. Roxbury, M. Strano, J. M. Tour, R. B. Weisman, W. Wenseleers, M. Yudasaka, Nat. Nanotechnol. 2020, 15, 164. 
[200] B. Fadeel, C. Bussy, S. Merino, E. Vazquez, E. Flahaut, F. Mouchet, L. Evariste, L. Gauthier, A. J. Koivisto, U. Vogel, C. Martin, L. G. Delogu, T. Buerki-Thurnherr, P. Wick, D. Beloin-Saint-Pierre, R. Hischier, M. Pelin, F. Candotto Carniel, M. Tretiach, F. Cesca, F. Benfenati, D. Scaini, L. Ballerini, K. Kostarelos, M. Prato, A. Bianco, ACS Nano 2018, 12, 10582.

[201] R. Alshehri, A. M. Ilyas, A. Hasan, A. Arnaout, F. Ahmed, A. Memic, J. Med. Chem. 2016, 59, 8149.

[202] K. Bhattacharya, S. P. Mukherjee, A. Gallud, S. C. Burkert, S. Bistarelli, S. Bellucci, M. Bottini, A. Star, B. Fadeel, Nanomedicine 2016, 12, 333.

[203] C. Martin, K. Kostarelos, M. Prato, A. Bianco, Chem. Commun. 2019, 55, 5540.

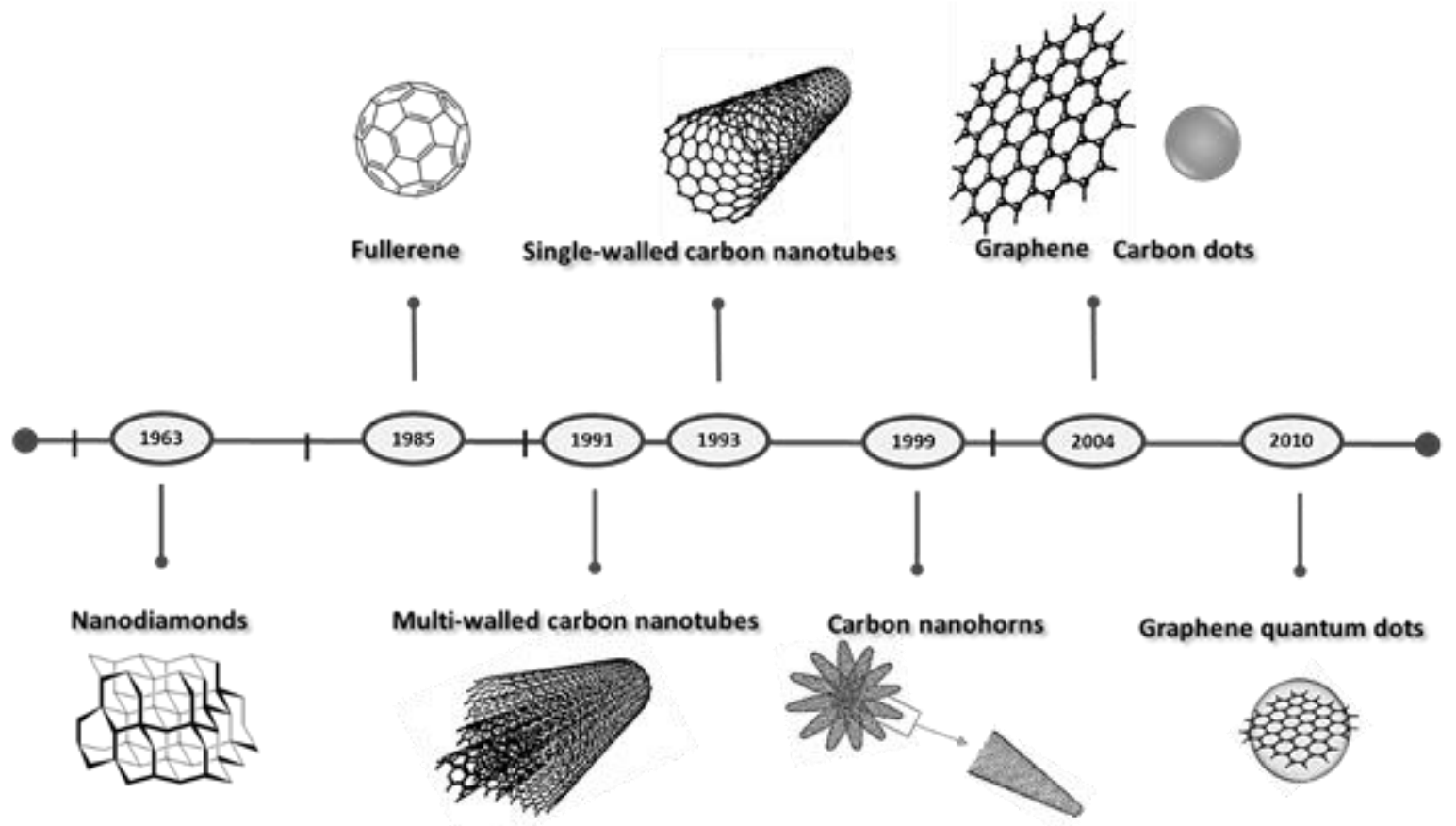

Figure 1. Timeline of the discovery of carbon nanomaterials. 


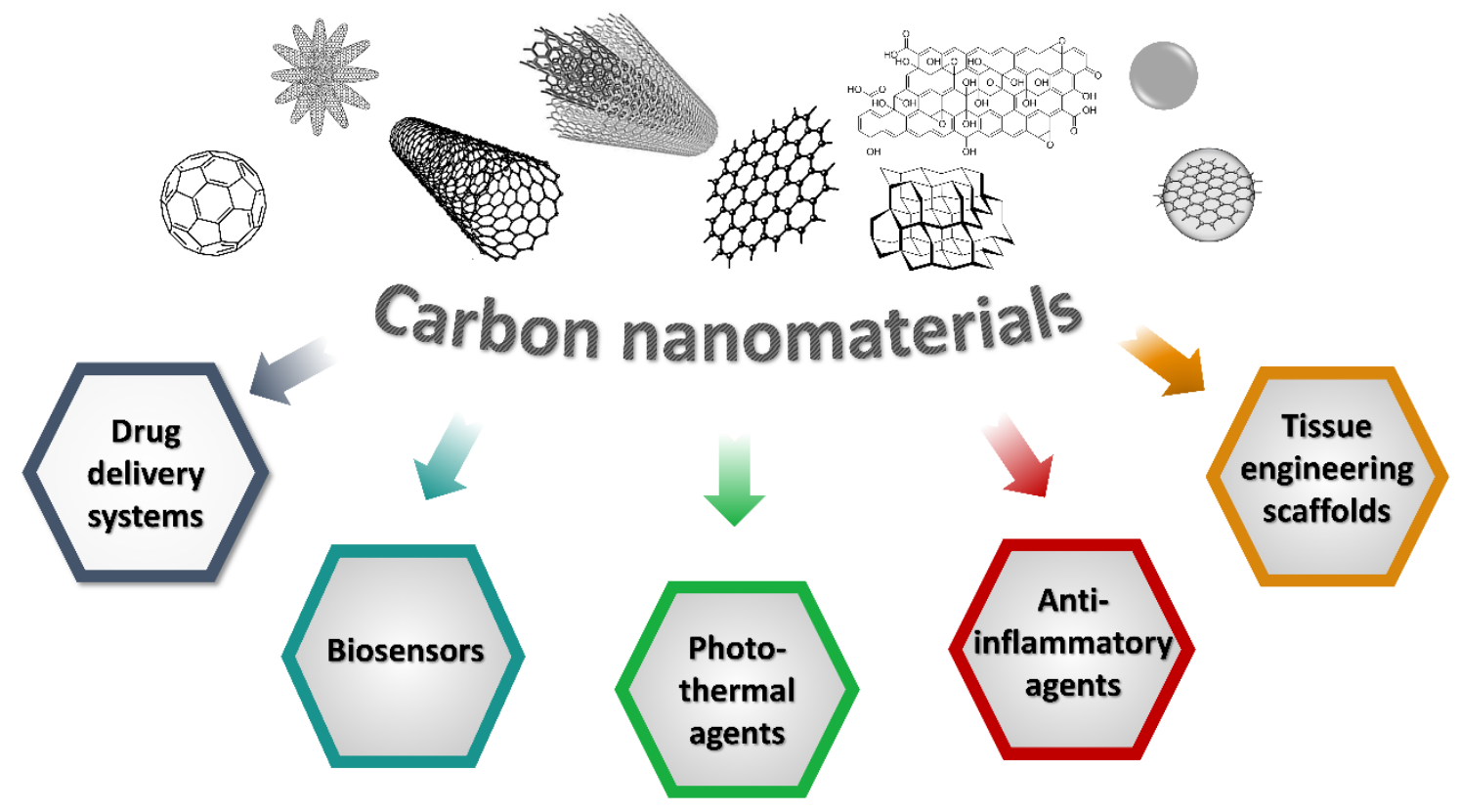

Figure 2. Examples of applications of carbon nanomaterials in the biomedical field.
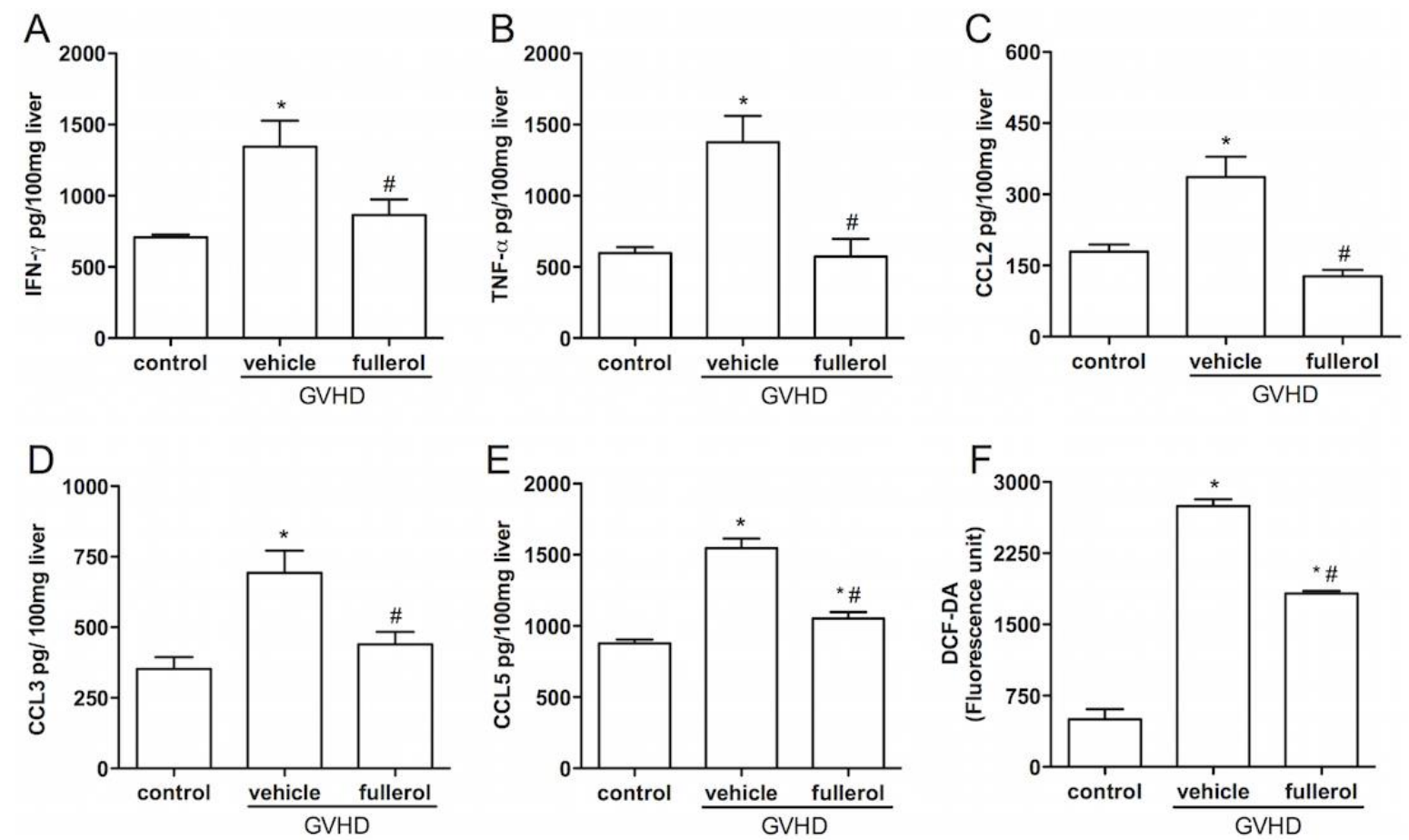

Figure 3. Fullerol reduction of the concentration of cytokines, chemokines, and ROS in the liver of fullerol-treated GVHD mice. Reproduced with permission. ${ }^{[46]}$ Copyright 2015, PLOS One. 


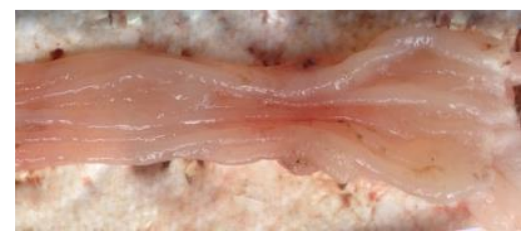

1

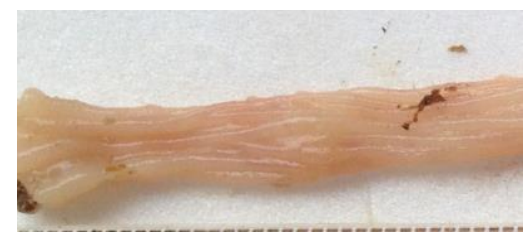

2

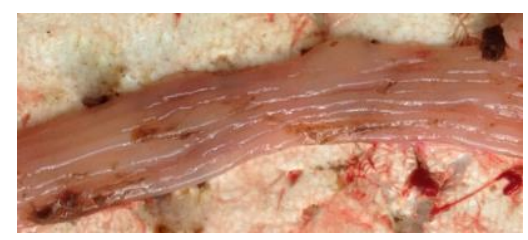

3

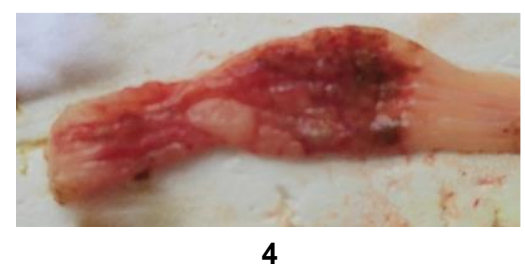

4
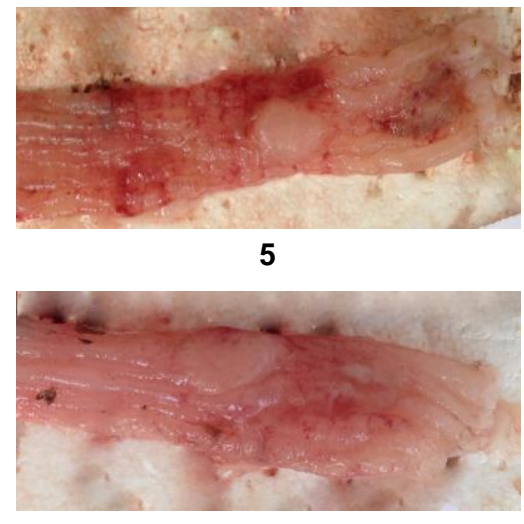

6

Figure 4. Photographs of colon internal sides for control rats (1) non-treated and treated with FAS via (2) intraperitoneal administration or (3) intrarectal administration; acute colitis rats (4) non treated and treated with FAS by (5) intraperitoneal administration or (6) intrarectal administration. Reproduced with permission. ${ }^{[49]}$ Copyright 2018, Elsevier.

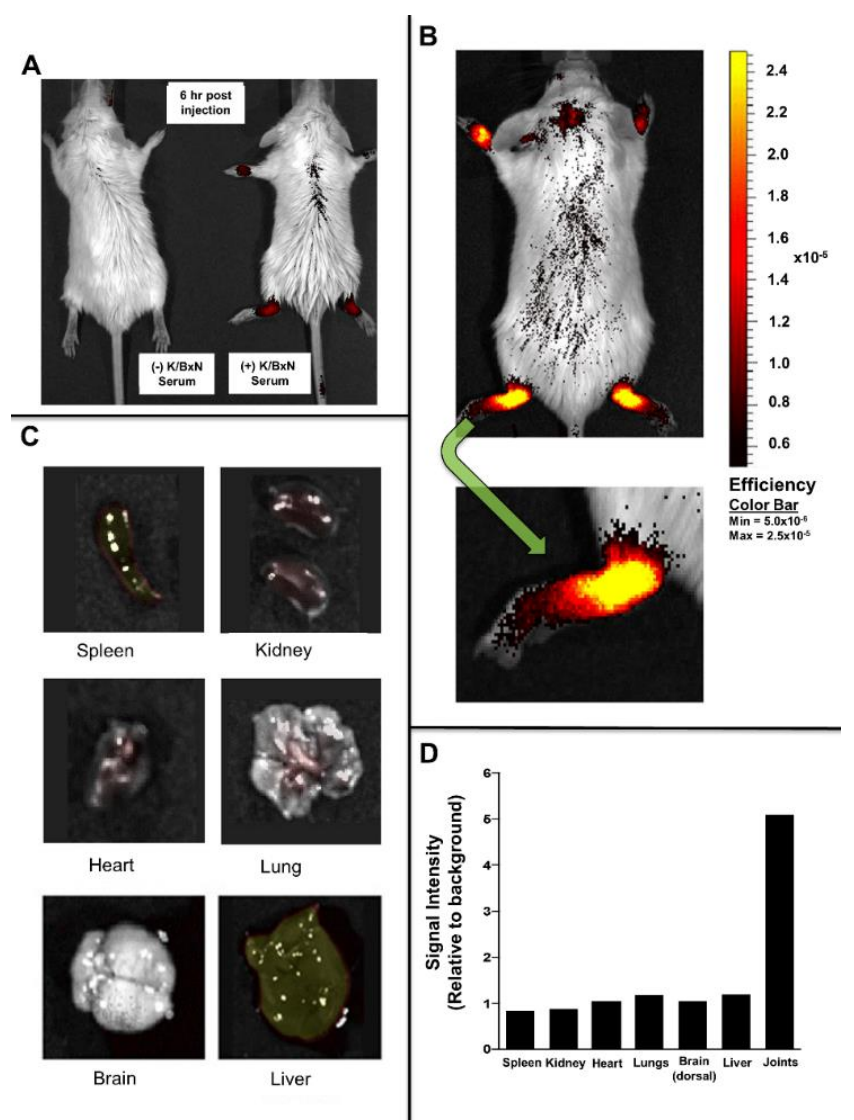

Figure 5. (A) Fluorescence imaging of non-arthritic control (left) and arthritic (right) mice $6 \mathrm{~h}$ after intravenous injection of fullerene conjugated to IRDye $800 \mathrm{CW}$. Imaging of (B) whole mouse and (C) externalized organs $24 \mathrm{~h}$ post-injection. (D) Quantification of fullerene dye concentration in representative organs from the mouse in (B) and (C). Reproduced with permission. ${ }^{[51]}$ Copyright 2015, PLOS One. 
A
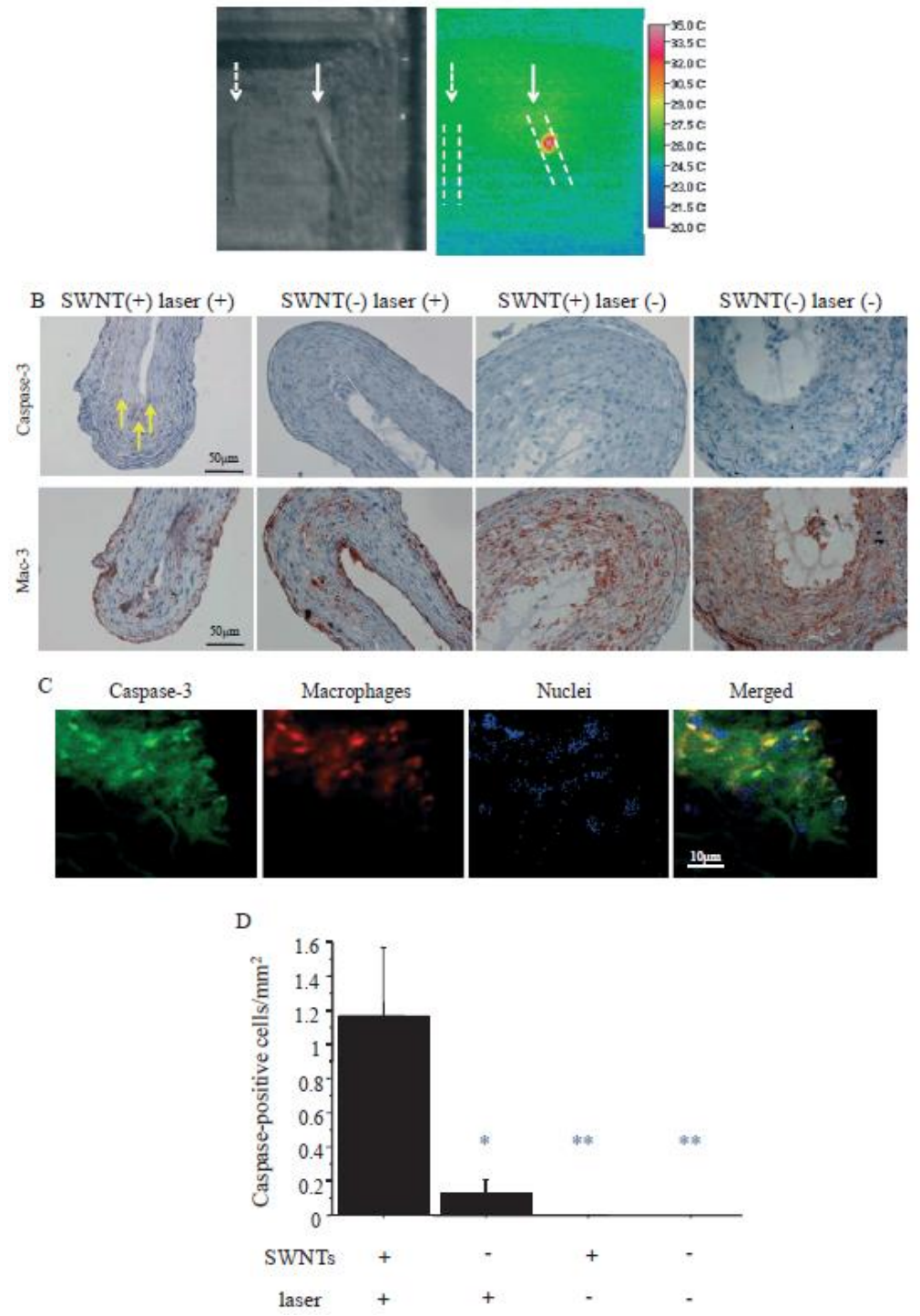

Figure 6. (A) White light image (left) and thermal image (right) of ex vivo ligated left carotid arteries from mice. The white arrows show the temperature increase of a ligated left carotid artery from a mouse treated with the SWCNT-Cy5.5 conjugate (solid arrow), while no increase was observed for a ligated left carotid artery from a control mouse (dashed arrow). The dashed lines show outline of carotid arteries. (B) Immunohistochemistry for caspase-3 (upper) and macrophages (lower). The PTT treatment induced apoptosis in the ligated left carotid arteries from the treated mice. Yellow arrows show caspase-3-positive cells corresponding to macrophages. (C) Immunofluorescence staining for caspase-3 and macrophages confirming the colocalization (yellow) of caspase-3-positive cells (green) and macrophages (red). (D) Quantitative analysis of the number of caspase-3-positive cells. An increase was observed only in the ligated carotids from mice treated with the SWCNT-Cy5.5 conjugate upon laser light exposure. Reproduced with permission. ${ }^{[56]}$ Copyright 2012, J. Am. Heart Assoc. 


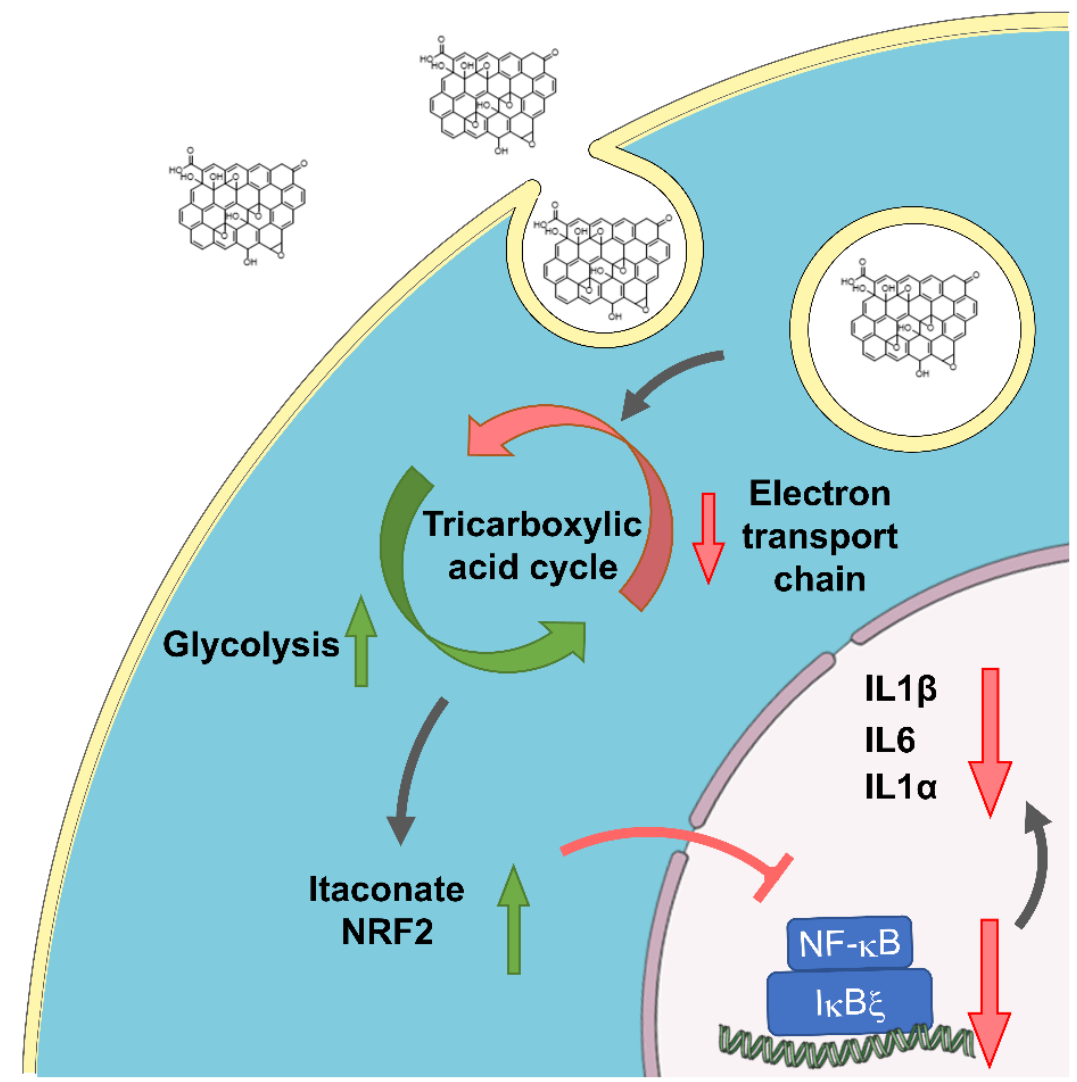

Figure 7. Proposed action mechanism of GO on metabolism and gene regulation.

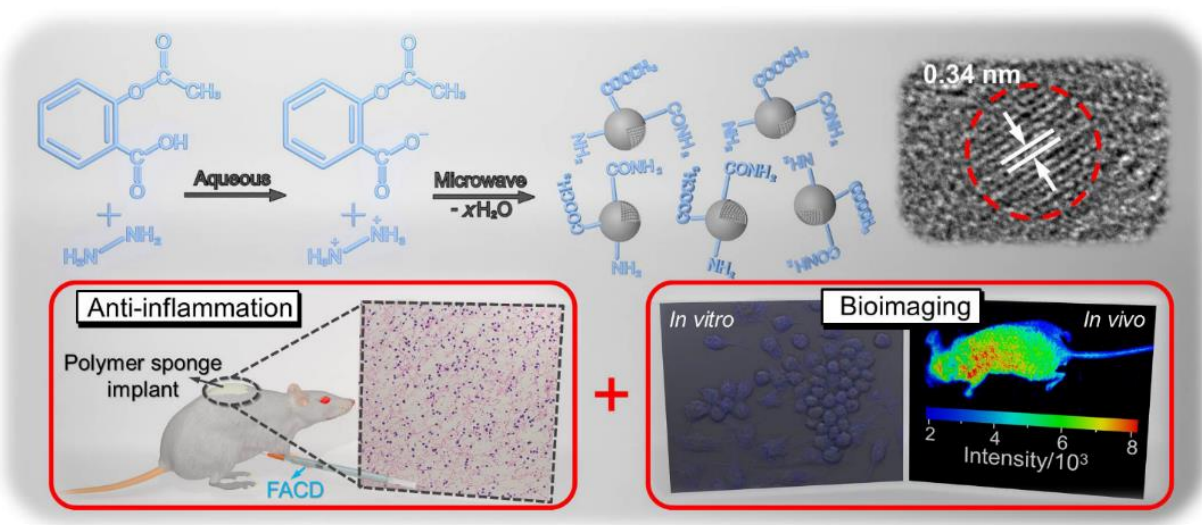

Figure 8. FACDs: preparation, high resolution transmission electron microscopy and dual use for cellular imaging/bioimaging and anti-inflammation. Reproduced with permission. ${ }^{[68]}$ Copyright 2016, American Chemical Society. 


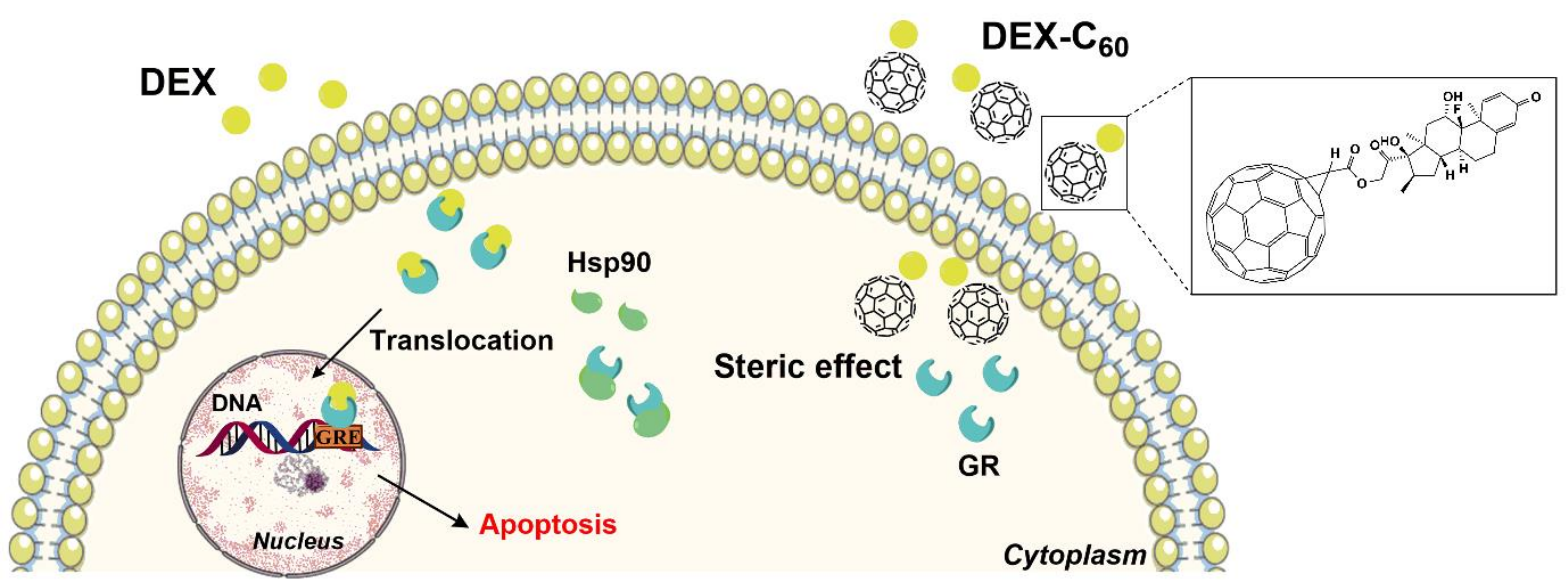

Figure 9. Toxicity mechanism of DEX involving the binding to GR, which is inhibited when the drug is conjugated to $\mathrm{C}_{60}$.

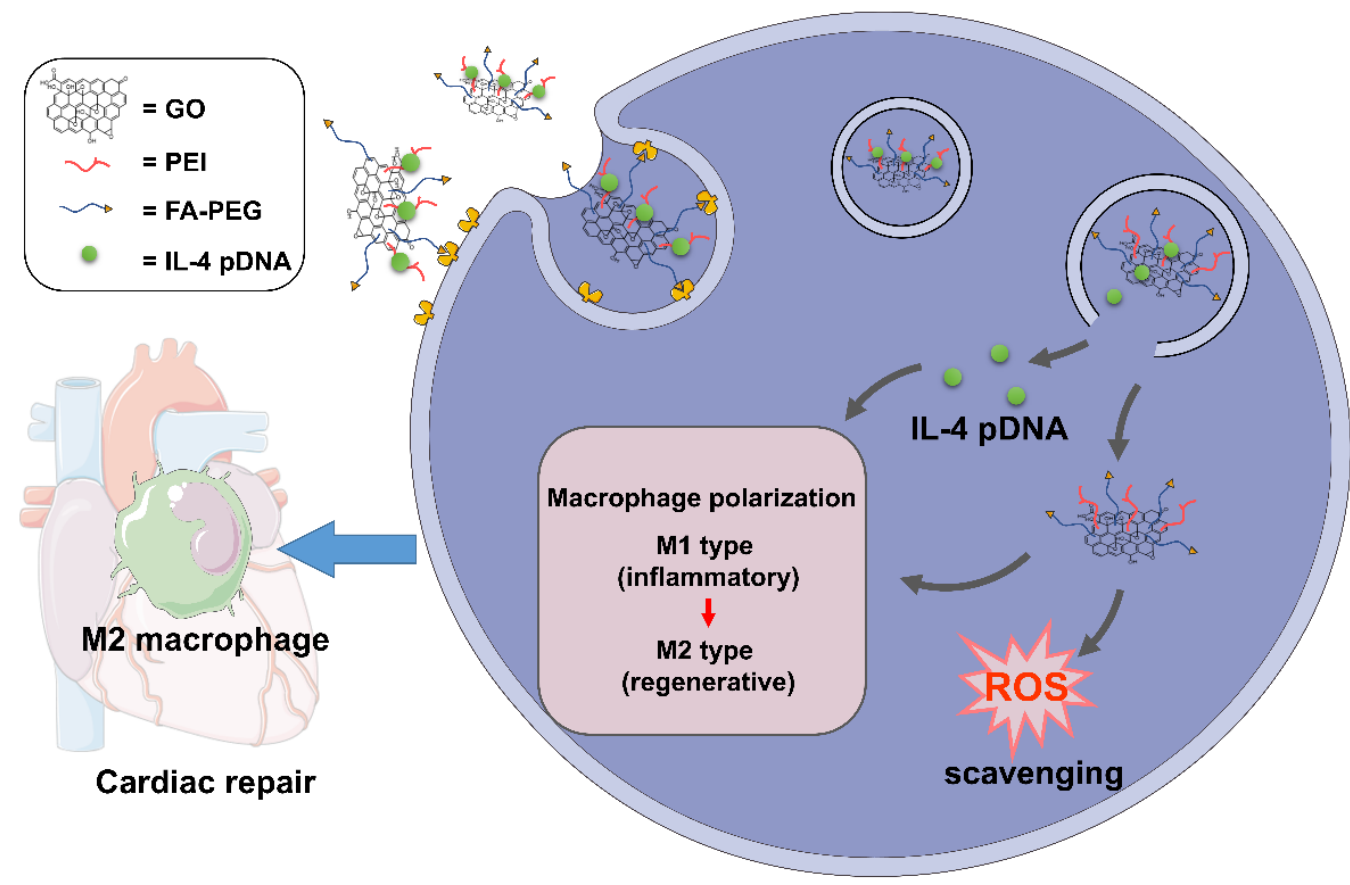

Figure 10. Proposed therapeutic mechanisms of IL-4 plasmid DNA (pDNA) adsorbed on functionalized GO in cardiac repair. 

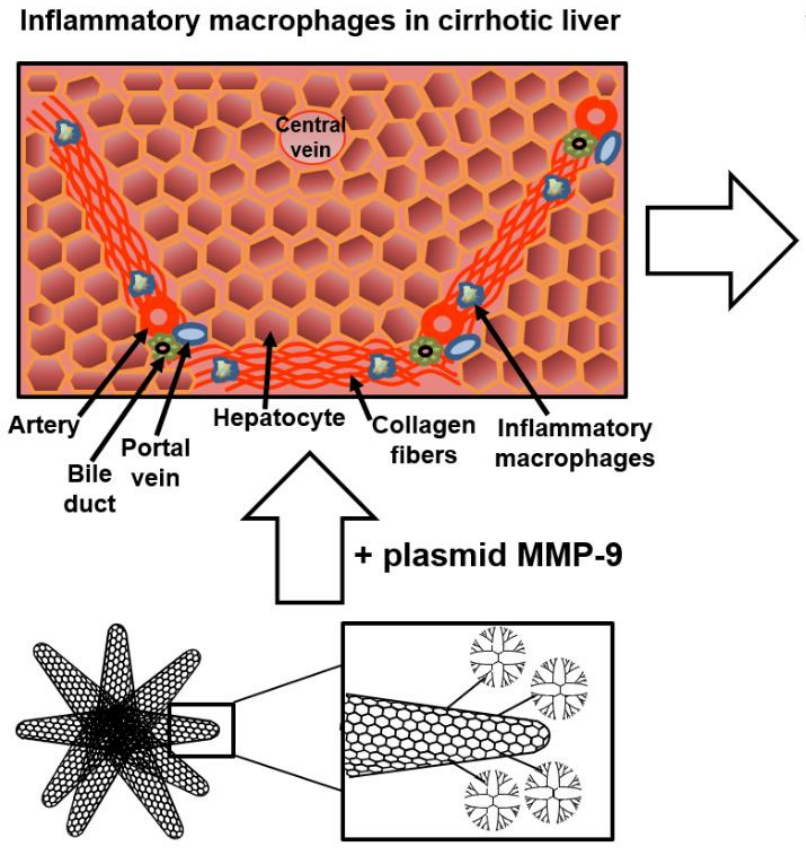

Graphene-dendrimer nanostars treated macrophages selectively digest fibers

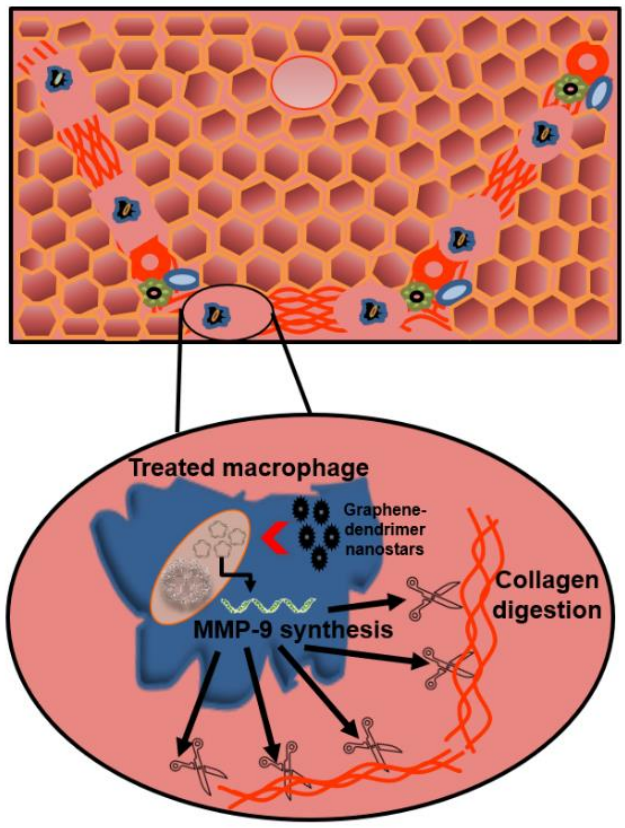

Macrophage-mediated precision therapy

Figure 11. Proposed action mechanism of pMMP-9-dendrimer-GNSs for hepatic fibrosis treatment. Reproduced with permission. ${ }^{[104]}$ Copyright 2018, American Chemical Society.

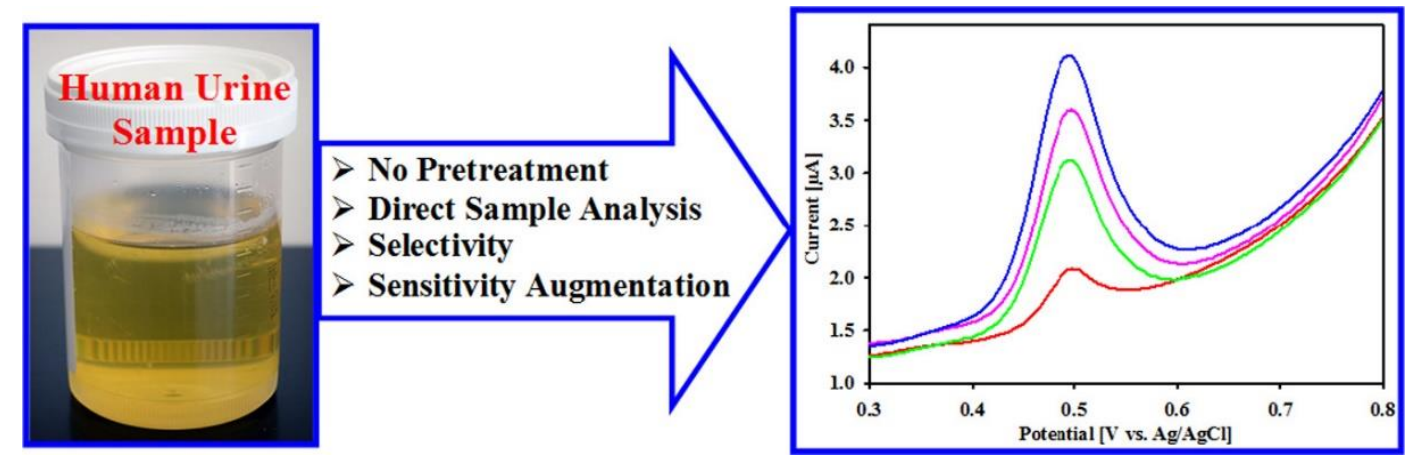

Figure 12. Enhancement in sensitivity of the detection of mefenamic acid using a CNT-based sensor by cyclic voltammetry. Reproduced with permission. ${ }^{[13]}$ Copyright 2017, Elsevier. 


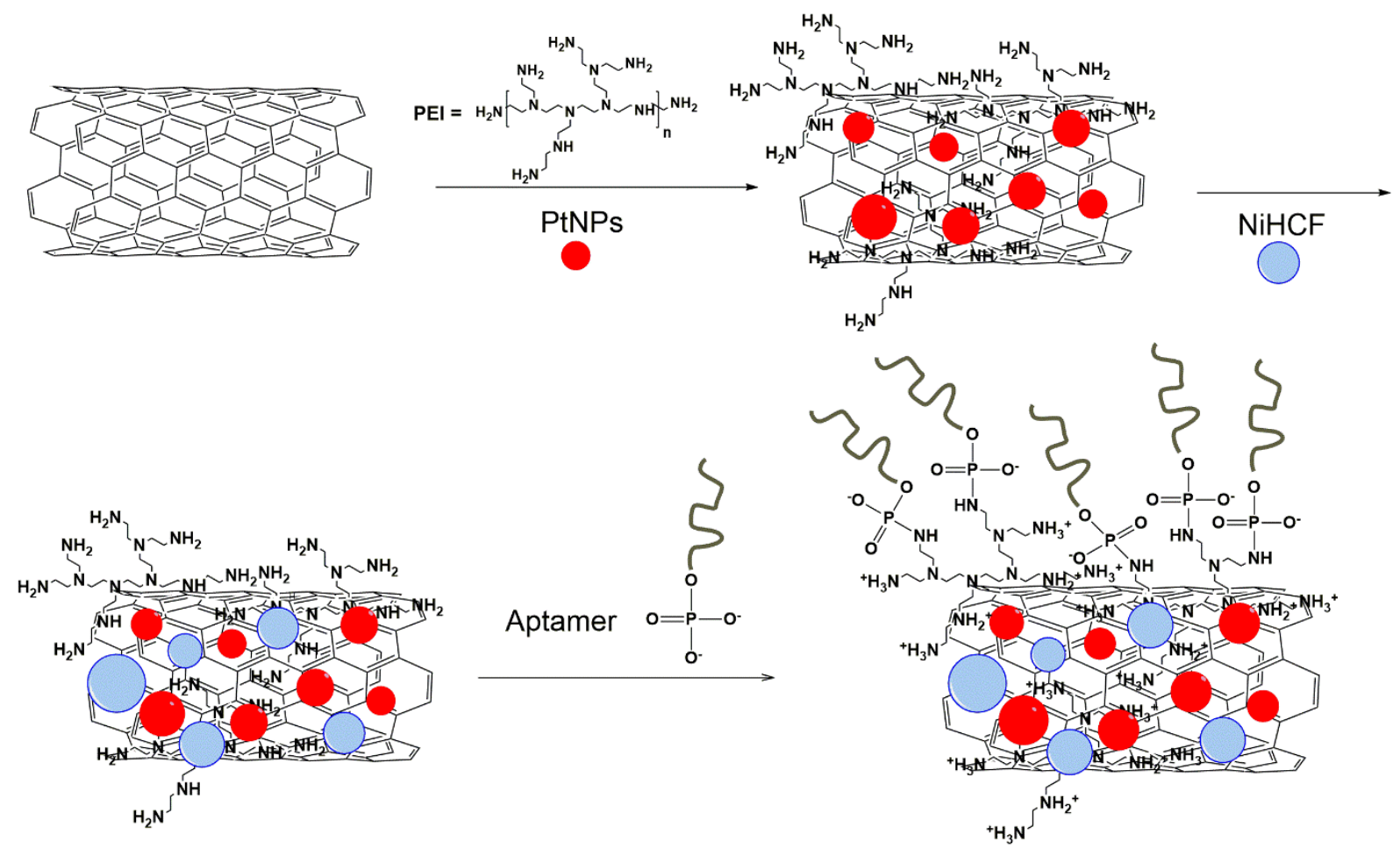

Figure 13. Fabrication of the aptasensor based on i) the PtNP-PEI-CNTs, ii) nickel hexacyanoferrate (NiHCF) electrodeposition, and iii) aptamer immobilization.

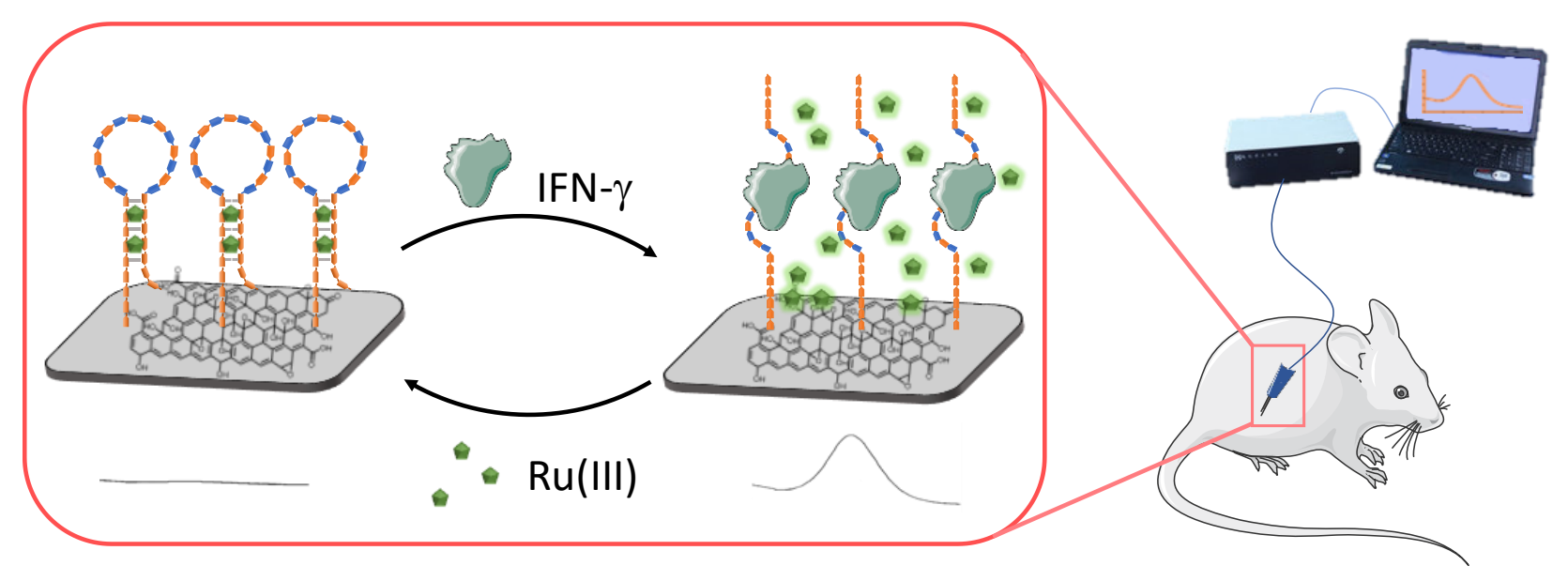

Figure 14. In vivo sensing device based on structure-switching aptamer for monitoring of IFN$\gamma$ in mice. 
Table 1. Carbon nanomaterials exploited for their intrinsic anti-inflammatory properties.

\begin{tabular}{|c|c|c|c|c|}
\hline $\begin{array}{c}\text { Carbon } \\
\text { nanomaterials }\end{array}$ & Diseases & Cell types & In vivo models & References \\
\hline $\begin{array}{l}\text { Bis-malonic acid } \\
\text { fullerene }\end{array}$ & $\begin{array}{l}\text { Inflammation (e.g, RA, } \\
\text { systemic lupus } \\
\text { erythematosus, systemic } \\
\text { sclerosis, inflammatory } \\
\text { bowel disease) }\end{array}$ & $\begin{array}{l}\text { Bone marrow-derived mast } \\
\text { cells from C57BL/6 mice }\end{array}$ & l & [45] \\
\hline Fullerol & Graft-versus-host disease & 1 & GVHD mouse model & [46] \\
\hline $\begin{array}{l}\text { Fullerene } \\
\text { (aqueous } \\
\text { solution) }\end{array}$ & Ulcerative colitis & l & Acute colitis rat model & [49] \\
\hline $\begin{array}{l}\text { Fullerene } \\
\text { (aqueous } \\
\text { solution) }\end{array}$ & Atopic dermatitis & $\begin{array}{l}\text { Ovalbumin-stimulated mouse } \\
\text { splenocytes }\end{array}$ & Atopic dermatitis mouse model & [50] \\
\hline $\begin{array}{l}\text { Functionalized } \\
\text { fullerenes }\end{array}$ & Rheumatoid arthritis & $\begin{array}{l}\text { BMMCs generated from } \\
\text { FCYRII-deficient mice \& } \\
\text { human fibroblasts from the } \\
\text { synovium of RA patients }\end{array}$ & $\begin{array}{l}\mathrm{K} / \mathrm{BxN} \text { serum transfer arthritis } \\
\text { mouse model and } \mathrm{CIA} \text { mouse } \\
\text { model }\end{array}$ & [51] \\
\hline SWCNTs & Inflammation & $\begin{array}{l}\text { RBL2H3 (rat basophilic } \\
\text { leukemia cells) }\end{array}$ & l & [53] \\
\hline $\begin{array}{l}\text { Cy5.5-labeled } \\
\text { SWCNTs coated } \\
\text { with PL-PEG }\end{array}$ & Atherosclerosis & RAW 264.7 macrophages & $\begin{array}{c}\text { Left carotid-ligated FVB mice after } \\
\text { induction of hyperlipidemia and } \\
\text { diabetes }\end{array}$ & [56] \\
\hline GO & $\begin{array}{l}\text { Inflammation (e.g., RA, } \\
\text { multiple sclerosis, } \\
\text { psoriasis, experimental } \\
\text { autoimmune encephalitis) }\end{array}$ & $\begin{array}{l}\text { iBMDMs/mixed glial cells } \\
\text { (microglial cells) }\end{array}$ & ( & [64] \\
\hline GO & Sepsis & $\begin{array}{l}\text { iNKT cells/regulatory T } \\
\text { cells/DCs }\end{array}$ & $\begin{array}{l}\alpha-G a l a c t o s y l c e r a m i d e-t r e a t e d \\
\text { mice }\end{array}$ & [65] \\
\hline GQDs & Inflammation & $\begin{array}{l}\text { DCs, phytohemagglutinin- } \\
\text { stimulated PBMCs }\end{array}$ & l & [66] \\
\hline GQDs & $\begin{array}{l}\text { Experimental autoimmune } \\
\text { encephalomyelitis }\end{array}$ & Th1 cells & EAE mouse model & [67] \\
\hline
\end{tabular}




\begin{tabular}{|c|c|c|c|c|}
\hline CDs & Acute inflammation & $\begin{array}{c}\text { Lipopolysaccharide (LPS)- } \\
\text { activated RAW 264.7 } \\
\text { macrophages }\end{array}$ & Acute inflammation rat model \\
\hline
\end{tabular}

Table 2. Carbon nanomaterials exploited as carriers for the delivery of anti-inflammatory agents.

\begin{tabular}{|c|c|c|c|c|c|c|}
\hline $\begin{array}{c}\text { Carbon } \\
\text { nanomaterials }\end{array}$ & Diseases & $\begin{array}{l}\text { Bioactive } \\
\text { molecules }\end{array}$ & $\begin{array}{c}\text { Type of } \\
\text { functionalization }\end{array}$ & Cell types & In vivo models & References \\
\hline Fullerene & $\begin{array}{l}\text { Inflammation } \\
\text { (e.g., RA) }\end{array}$ & Dexamethasone & Covalent & Thymocytes & 1 & [72] \\
\hline Fullerene & $\begin{array}{c}\text { Inflammation } \\
\text { (e.g., RA, } \\
\text { psoriasis, } \\
\text { multiple } \\
\text { sclerosis, } \\
\text { asthma) } \\
\end{array}$ & Pentoxifylline & Covalent & $\begin{array}{l}\text { LPS-activated } \\
\text { reticulum sarcoma } \\
\text { cell line J774A.1 }\end{array}$ & I & [73] \\
\hline Fullerene & $\begin{array}{c}\text { Inflammation } \\
\text { (e.g., RA, } \\
\text { psoriasis, } \\
\text { multiple } \\
\text { sclerosis, } \\
\text { asthma) }\end{array}$ & Thalidomide & Covalent & $\begin{array}{l}\text { LPS-stimulated RAW } \\
264.7 \text { macrophages }\end{array}$ & I & [74] \\
\hline MWCNTs & Inflammation & Dexamethasone & $\begin{array}{c}\text { Non-covalent } \\
\text { (encapsulation) }\end{array}$ & $\begin{array}{l}\text { LPS-activated HAPI } \\
\text { cells }\end{array}$ & l & [76] \\
\hline MWCNTs & RA & Triamcinolone & Non-covalent & $\begin{array}{l}\text { TNF- } \alpha \text {-stimulated } \\
\text { FLSs from RA } \\
\text { patients }\end{array}$ & I & [77] \\
\hline MWCNTs & RA & Dexamethasone & Non-covalent & $\begin{array}{l}\text { TNF- } \alpha \text {-stimulated } \\
\text { FLSs from RA } \\
\text { patients }\end{array}$ & I & [79] \\
\hline MWCNTs & $\begin{array}{c}\text { Inflammation } \\
\text { (e.g., Crohn's } \\
\text { disease, } \\
\text { ulcerative } \\
\text { colitis, asthma) }\end{array}$ & Budesonide & Non-covalent & $\begin{array}{c}\text { RAW } 264.7 \\
\text { macrophages and } \\
\text { LPS-activated } \\
\text { primary peritoneal } \\
\text { murine macrophages }\end{array}$ & I & [80] \\
\hline
\end{tabular}




\begin{tabular}{|c|c|c|c|c|c|c|}
\hline GO & Inflammation & $\begin{array}{c}\text { Zwitterionic } \\
\text { chitosan \& } \\
\text { nystatin } \\
\end{array}$ & Non-covalent & $\begin{array}{l}\text { LPS-challenged } \\
\text { macrophages }\end{array}$ & l & [82] \\
\hline MWCNTs & RA & Methotrexate & Non-covalent & l & $\begin{array}{l}\text { Carrageenan- } \\
\text { induced arthritis } \\
\text { rats }\end{array}$ & [83] \\
\hline MWCNTs & Colitis & $\begin{array}{c}2- \\
\text { Arachidonoylgly } \\
\text { cerol }\end{array}$ & Non-covalent & $\begin{array}{c}\text { Rat } \\
\text { pheochromocytoma } \\
\text { PC12 cells }\end{array}$ & Colitic rats & {$[84]$} \\
\hline SWCNTs & Atherosclerosis & $\begin{array}{c}\text { Chemical } \\
\text { inhibitor of the } \\
\text { antiphagocytic } \\
\text { CD47-SIRPa } \\
\text { signaling axis }\end{array}$ & Non-covalent & $\begin{array}{c}\text { Murine (RAW264.7) } \\
\text { and human (THP-1) } \\
\text { macrophages }\end{array}$ & $\begin{array}{c}\text { Atheroprone } \\
\text { apolipoprotein- } \\
\text { E-deficient mice }\end{array}$ & [85] \\
\hline SWCNHs & RA & Prednisolone & Non-covalent & l & $\mathrm{CIA}$ rats & [87] \\
\hline GO & Osteoarthritis & BMP-2 & Non-covalent & $\begin{array}{c}\text { Bone marrow stem } \\
\text { cells and } \\
\text { chondrocytes }\end{array}$ & $\begin{array}{l}\text { Osteoarthritic } \\
\text { rats }\end{array}$ & [89] \\
\hline GO & $\begin{array}{l}\text { Myocardial } \\
\text { infarction }\end{array}$ & $\begin{array}{c}\text { IL-4 plasmid } \\
\text { DNA }\end{array}$ & Non-covalent & $\begin{array}{c}\text { LPS-stimulated } \\
\text { bone-marrow-derived } \\
\text { macrophages }\end{array}$ & MI mice & [99] \\
\hline CDs & $\begin{array}{l}\text { Inflammation } \\
\text { during cartilage } \\
\text { defect therapy }\end{array}$ & siTNF- $\alpha$ & Non-covalent & MSCs & $\begin{array}{c}\text { Cartilage defect } \\
\text { induced in SD } \\
\text { rats }\end{array}$ & [102] \\
\hline $\begin{array}{l}\text { Graphene } \\
\text { nanostars }\end{array}$ & Liver cirrhosis & pMMP-9 & Non-covalent & $\begin{array}{c}\text { TNF- } \alpha \text {-stimulated } \\
\text { RAW } 264.7 \\
\text { macrophages } \\
\end{array}$ & Cirrhotic mice & [104] \\
\hline NDs & RA & Dexamethasone & Non-covalent & $\begin{array}{c}\text { IFN-y \& LPS- } \\
\text { activated primary } \\
\text { human } \\
\text { macrophages, IL-4 \& } \\
\text { IL-13-activated } \\
\text { primary human } \\
\text { macrophages }\end{array}$ & CIA mice & {$[107,108]$} \\
\hline
\end{tabular}


Table 3. Carbon nanomaterials used for the development of biosensors to detect anti-inflammatory drugs and inflammation-related biomarkers.

\begin{tabular}{|c|c|c|c|c|c|c|c|}
\hline $\begin{array}{c}\text { Carbon } \\
\text { nanomaterials }\end{array}$ & Diseases & Analytes & Probes & Detection media & Detection methods & $\begin{array}{l}\text { Detection } \\
\text { limits }\end{array}$ & References \\
\hline SWCNTS & $\begin{array}{c}\text { Inflammation } \\
\text { (e.g., RA) }\end{array}$ & $\begin{array}{l}\text { Mefenamic } \\
\text { acid }\end{array}$ & I & $\begin{array}{c}\text { Human urine \& } \\
\text { pharmaceutical } \\
\text { formulations }\end{array}$ & $\begin{array}{l}\text { Square wave } \\
\text { voltammetry }\end{array}$ & $13.4 \mathrm{nM}$ & [113] \\
\hline SWCNTS & $\begin{array}{l}\text { Rheumatoid } \\
\text { arthritis }\end{array}$ & $\begin{array}{l}\text { Autoantibodies } \\
\text { to citrulline- } \\
\text { containing } \\
\text { peptides }\end{array}$ & $\begin{array}{c}\text { RA specific } \\
\text { citrulline-modified } \\
\text { version of a 14- } \\
\text { mer cyclic } \\
\text { filaggrin peptide }\end{array}$ & $\begin{array}{c}\text { Serum from } \\
\text { rheumatoid } \\
\text { arthritis patients }\end{array}$ & $\begin{array}{l}\text { Quartz crystal } \\
\text { microbalance }\end{array}$ & l & [114] \\
\hline SWCNTS & $\begin{array}{c}\text { Cardiovascular } \\
\text { diseases }\end{array}$ & $\begin{array}{l}\text { C-reactive } \\
\text { protein }\end{array}$ & $\begin{array}{l}\text { Anti-CRP } \\
\text { antibodies }\end{array}$ & $\begin{array}{c}\text { Human blood } \\
\text { serum }\end{array}$ & $\begin{array}{c}\text { Electrical current } \\
\text { measurement }\end{array}$ & $1 \times 10^{-4} \mu \mathrm{g} \cdot \mathrm{mL}^{-1}$ & [117] \\
\hline MWCNTs & $\begin{array}{c}\text { Acute and } \\
\text { chronic joint } \\
\text { inflammation }\end{array}$ & Diclofenac & $\begin{array}{l}\text { Diclofenac- } \\
\text { aptamer }\end{array}$ & $\begin{array}{l}\text { Human urine \& } \\
\text { pharmaceutical } \\
\text { formulations }\end{array}$ & $\begin{array}{l}\text { Impedance } \\
\text { spectroscopy }\end{array}$ & $2.7 \mathrm{nM}$ & {$[121]$} \\
\hline ER-GONRs & $\begin{array}{c}\text { Inflammation } \\
\text { (e.g., RA, } \\
\text { osteoarthritis) } \\
\end{array}$ & Nimesulide & l & Human urine & Cyclic voltammetry & $3.5 \mathrm{nM}$ & [128] \\
\hline rGO & $\begin{array}{l}\text { Inflammatory } \\
\text { bowel disease }\end{array}$ & Lysozyme & $\begin{array}{c}\text { Lysozyme- } \\
\text { specific aptamer }\end{array}$ & $\begin{array}{c}\text { Serum from IBD } \\
\text { patients }\end{array}$ & $\begin{array}{c}\text { Differential pulse } \\
\text { voltammetry }\end{array}$ & $200 \mathrm{fM}$ & [133] \\
\hline GO & Enteritis & $\mathrm{IFN}-\gamma$ & $\begin{array}{l}\text { IFN- } \gamma \text {-specific } \\
\text { aptamer/Ru(III) }\end{array}$ & $\begin{array}{l}\text { In vivo (tissue of } \\
\text { enteritis mice) }\end{array}$ & $\begin{array}{c}\text { Square wave } \\
\text { voltammetry \& } \\
\text { chronoamperometry }\end{array}$ & $1.3 \mathrm{pg} \cdot \mathrm{mL}^{-1}$ & [139] \\
\hline
\end{tabular}


Dr. Cécilia Ménard-Moyon obtained her PhD in 2005 at Commissariat à l'Energie Atomique et aux Energies Alternatives (CEA)/Saclay (France). After a 1-year postdoc at the University of York (UK) and 18 months in industry (Belgium), she joined the group of Dr. Alberto Bianco in Strasbourg as CNRS researcher in 2008. Her research interests are focused on the functionalization of carbon-based nanomaterials for biomedical applications, the self-assembly of amino acid derivatives and peptides, as well as the formation of hydrogels for on-demand drug delivery.

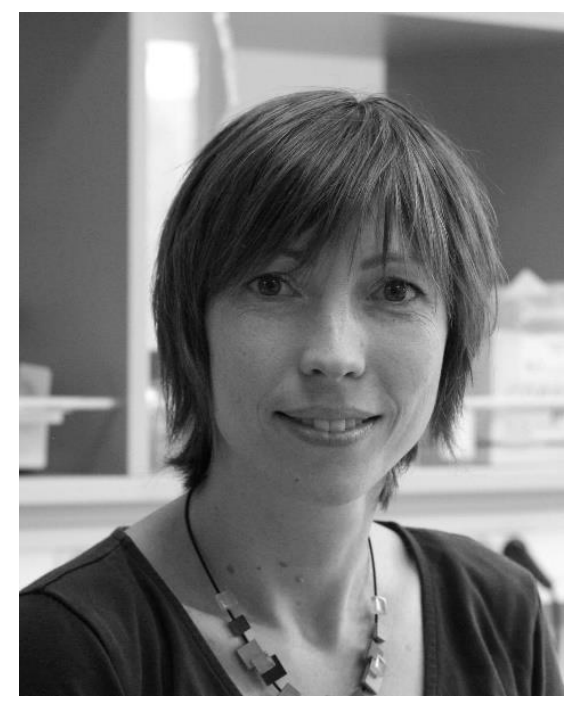

Dr. Alberto Bianco received his PhD in 1996 from the University of Padova. As a visiting scientist, he worked at the University of Lausanne, the University of Tübingen (as an Alexander von Humboldt fellow), the University of Padova and Kyoto University. He is currently Research Director at the CNRS in Strasbourg. His research interests focus on the design of multifunctional carbon-based nanomaterials for therapy, diagnostics and imaging. 


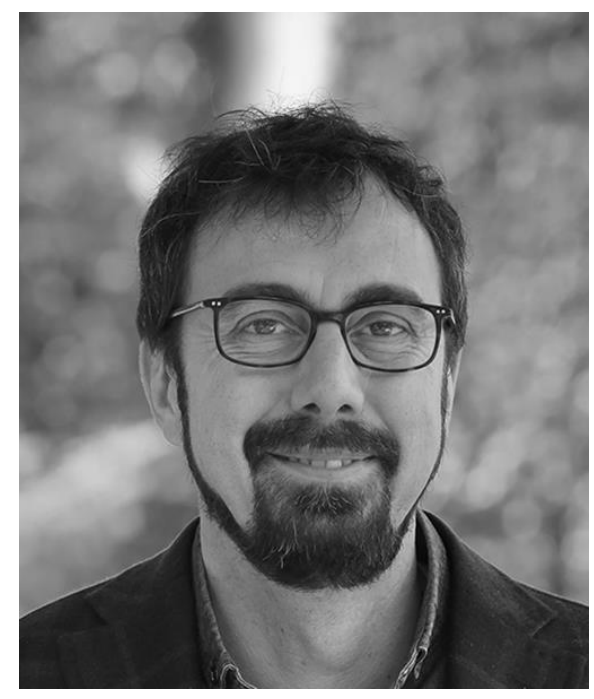


Carbon nanomaterials have been extensively investigated in nanomedicine, mainly for cancer therapy and to a lower extent for inflammatory diseases. This review presents their intrinsic anti-inflammatory properties, their use as carriers of anti-inflammatory drugs, as biosensors and for blood purification, as well as their potential for clinical translation for the diagnosis and treatment of inflammatory diseases.

Keyword carbon nanomaterials

R. Soltani,\# S. Guo,\# A. Bianco,* C. Ménard-Moyon*

\#These authors contributed equally.

Title Carbon nanomaterials applied for the treatment of inflammatory diseases: preclinical evidence

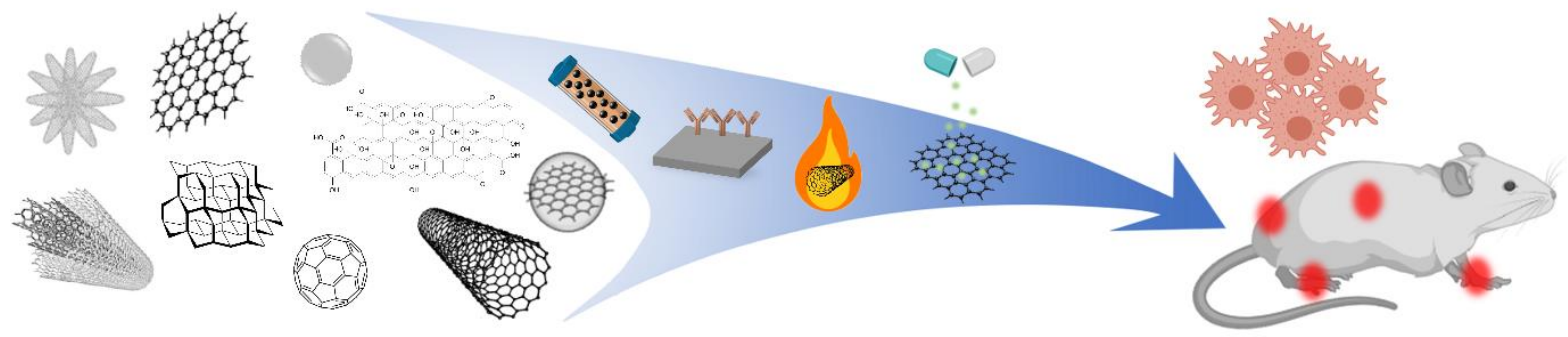

